\title{
Altered tRNA dynamics during translocation on slippery mRNA as determinant of spontaneous ribosome frameshifting
}

\author{
Panagiotis Poulis \\ MPI-NAT \\ Anoshi Patel \\ MPI-NAT \\ Marina Rodnina \\ MPI-NAT \\ Sarah Adio ( $\square$ sarah.adio@uni-goettingen.de) \\ University of Göttingen https://orcid.org/0000-0002-6555-0850
}

\section{Article}

Keywords:

Posted Date: January 31st, 2022

DOI: https://doi.org/10.21203/rs.3.rs-1269048/v1

License: (a) (i) This work is licensed under a Creative Commons Attribution 4.0 International License. Read Full License

Version of Record: A version of this preprint was published at Nature Communications on July 22nd, 2022. See the published version at https://doi.org/10.1038/s41467-022-31852-w. 


\section{Altered tRNA dynamics during translocation on slippery mRNA as determinant of spontaneous ribosome frameshifting}

Panagiotis Poulis ${ }^{1}$, Anoshi Patel ${ }^{2}$, Marina V. Rodnina ${ }^{1} \&$ Sarah $_{\text {Adio }}^{2 *}$

${ }^{1}$ Department of Physical Biochemistry, Max Planck Institute for Multidisciplinary Sciences, Göttingen, Germany

${ }^{2}$ Department of Molecular Structural Biology, Institute for Microbiology and Genetics, Georg-August University of Göttingen, Göttingen, Germany

*correspondence to sarah.adio@uni-goettingen.de 


\section{Abstract}

When reading consecutive mRNA codons, ribosomes move by exactly one triplet at a time to synthesize a correct protein. Some mRNA tracks, called slippery sequences, are prone to ribosomal frameshifting, because the same tRNA can read both 0 - and -1-frame codon. Using smFRET we show that during EF-Gcatalyzed translocation on slippery sequences a fraction of ribosomes switches from rapid, accurate translation to a slow, frameshifting-prone translocation mode where the movements of peptidyl- and deacylated tRNA become uncoupled. While deacylated tRNA translocates rapidly, pept-tRNA continues to fluctuate between chimeric and posttranslocation states, which slows down the re-locking of the small ribosomal subunit head domain. After rapid release of deacylated tRNA, pept-tRNA gains unconstrained access to the -1-frame triplet, resulting in slippage followed by recruitment of the-1-frame aa-tRNA into the A site. Our data show how altered choreography of tRNA and ribosome movements reduces the translation fidelity of ribosomes translocating in a slow mode. 


\section{Introduction}

During translation elongation, the ribosome moves along the mRNA in steps of three nucleotides, i.e. one codon at a time, towards the mRNA $3^{\prime}$ end. The exact step size is essential, as it maintains the correct open reading frame until the ribosome encounters a stop codon that terminates translation. However, in some cases, ribosomes can switch from the original open reading frame ( 0 -frame) into alternative $-1,+1$, +2 or -4 frames. Frameshifting usually occurs on "slippery" mRNA sequences which allow tRNAs to base pair with codons in both the original and an alternative frame. In programmed ribosome frameshifting, which is most prevalent in viruses, additional secondary structure elements in the mRNA facilitate frameshifting, resulting in two functional protein products that are usually essential for virus propagation ${ }^{1}$, $2,3,4,5,6,7$. In contrast, in most cases where slippage is spontaneous, -1 frameshifting results in out-offrame decoding and termination at premature stop codons leading to synthesis of aberrant dysfunctional proteins $^{8,9,10}$. The genomic abundance of slippery sequences is relatively high. In E. coli, the slippery A AAA AAG sequence is found in 68 genes $^{11}$ and in humans $10 \%$ of all cellular mRNAs contain a slippery sequence $^{12}$. However, the frequency of spontaneous frameshifting in vivo is as low as $10^{-4}-10^{-5}$ during canonical translation ${ }^{13,14}$, even though some slippery sequences actually favor codon-anticodon pairing in the -1 frame ${ }^{15}$. This implies existence of a mechanism preventing the loss of the correct reading frame at slippery sites. Recent studies demonstrate that elongation factor G (EF-G) has a key role in reading frame maintenance during tRNA-mRNA translocation ${ }^{16,17,18,19}$.

Translocation is a complex process that entails movements of the ribosome, tRNAs and mRNA. EF-G binding to pretranslocation (PRE) complexes, which comprises ribosomes with the mRNA-bound peptidyltRNA in the A site and deacylated tRNA in the P site, facilitates the movement of tRNAs into the hybrid states $\left(\mathrm{A} / \mathrm{P}, \mathrm{A} / \mathrm{P}^{*}\right.$ and $\left.\mathrm{P} / \mathrm{E}\right)$, as well as rotation of small (SSU) and large (LSU) ribosomal subunits relative to each other $20,21,22,23,24,25,26,27$. GTP hydrolysis by EF-G and the subsequent Pi release promote largescale rearrangement of the complex that uncouples the movements of the head and body domains of the SSU. The tRNA anticodons and the mRNA move with the SSU head domain in forward direction, whereas the SSU body domain rotates backwards relative to LSU. As a result, tRNAs move into chimeric states (CHI or ap/P, pe/E), where the anticodons bind between the $A$ and $P$ and $P$ and $E$ sites on the SSU and the acceptor ends reside in the $P$ and $E$ site of the LSU, respectively ${ }^{19,20,23,26,28,29,30,31,32}$. Subsequently, tRNAs move synchronously to post translocation states $(P / P \text { and } E / E)^{23,26}$. At the end of translocation, the deacylated tRNA and EF-G dissociate from the ribosome and the SSU head domain swivels backwards locking pept-tRNA in the $P$ site $23,26,28,31$. 
Structural studies and kinetic analysis of translocation suggest how EF-G contributes to the reading frame maintenance. When ribosomes enter the $\mathrm{CHI}$ state the stabilizing interactions between the tRNAmRNA complex and 16S rRNA on the SSU body domain are lost and instead the complex interacts with the residues at the tip of EF-G domain 4, in particular H583 and Q507 $19,30,31$. In the absence of EF-G, the movements of the mRNA and tRNA anticodon become uncoupled and may lead to frameshifting ${ }^{18}$. Amino acid replacements at the tip of EF-G domain 4 promote -1 frameshifting on a slippery mRNA ${ }^{16,17}$. These replacements slow down translocation ${ }^{16,20,33}$ and alter the timing of translocation events, i.e. the backward movement of the SSU head from the swiveled to the non-swiveled state is delayed and uncoupled from the release of the deacylated tRNA from the $E$ site ${ }^{16}$. These two steps occur simultaneously during translocation with the wild type (wt) EF- $\mathrm{G}^{23,26}$ suggesting that rapid translocation and the EF-G-coordinated order of movements prevent spontaneous frameshifting.

While previous studies offered a conceptual framework for understanding reading frame maintenance, it remains unclear when and how spontaneous frameshifting occurs. Here we use smFRET to compare tRNA translocation pathways in the absence of frameshifting, i.e. on non-slippery mRNA, and at conditions where a significant fraction of ribosomes changes from 0 to -1 frame, i.e. on a slippery mRNA and with frameshifting-promoting EF-G mutants. This approach allows us to identify potential heterogeneity within the ribosome population, to visualize local tRNA fluctuations, and to monitor how internal movements of the ribosome control frameshifting. We identify two different modes of ribosome progression along the mRNA, a fast and accurate mode, where rapid simultaneous movement of pept-and deacylated tRNA is coupled to the motions of the ribosome, and a slow, frameshifting-prone mode with uncoupled translocation of pept- and deacylated tRNA. In the slow mode, pept-tRNA is trapped in fluctuations between $\mathrm{CHI}$ and $\mathrm{P} / \mathrm{P}$ states before accommodating in the $\mathrm{P}$ site, which occurs during back swivel of the SSU head domain. Deacylated tRNA translocates at normal speed and dissociates from the ribosome before the accommodation of pept-tRNA in the P site is completed. This opens a time window where a single pept-tRNA can reassign the reading frame according to thermodynamic potential of the mRNA sequence. Ribosomes favor the fast mode during translocation with wild-type EF-G, but switch to a slow mode during translocation by frameshifting-promoting EF-G mutants, which suggests that a population of ribosomes with distinct kinetic features contributes to the loss of reading frame on a slippery mRNA. 


\section{Results}

\section{Translocation of peptidyl-tRNA and ribosome frameshifting}

To dissect the mechanism of ribosome slippage, we first used smFRET to monitor translocation of pepttRNA from the $A$ to the P site upon addition of EF-G (Fig. 1a). We assembled PRE complexes on mRNA with or without a slippery sequence (Fig. 1b) and utilized FRET reporters attached to the ribosomal protein L11 (L11-Cy3) and pept-tRNA ${ }^{\text {Lys }}$-Cy5. On the non-slippery mRNA, tRNAs fluctuate between PRE states with FRET 0.8 and 0.6 until EF-G binds and then rapidly move to the P/P POST state (FRET 0.2) upon translocation (Fig. 1c, d). Steady-state smFRET experiments (Supplementary Fig. 1) and distance measurements based on the recent cryo-EM structures ${ }^{19,31,32}$ show that pept-tRNA in A/A and A/P states contribute to the FRET 0.8 state, whereas FRET 0.6 is consistent with the $A / P^{*}$ state that forms as the pept-tRNA elbow region and the CCA end move towards the P site. The transition from PRE to POST state occurs within $33 \mathrm{~ms}$, i.e. one camera frame in our experimental setup. The estimated lower limit for the translocation rate $\left(k_{T L} \geq 30 \mathrm{~s}^{-1}\right.$, Table 1$)$ agrees with ensemble in vitro translocation rates ranging between 7 and $30 \mathrm{~s}^{-1}$ at $22^{\circ} \mathrm{C}^{34,35,36}$. On the slippery mRNA, most ribosomes (81\%) show tRNA trajectories similar to those on non-slippery mRNA. However, on a fraction of ribosomes (19\%) the translocation trajectory appears different and pept-tRNA ${ }^{\text {Lys }}$-Cy5 transiently samples FRET 0.4 before reaching P/P (Fig. 1e, f). Previously, we and others have shown that FRET 0.4 corresponds to the $\mathrm{CHI}(\mathrm{ap} / \mathrm{P})$ state where the anticodon stem-loop of the tRNA resides between $\mathrm{A}$ and $\mathrm{P}$ site on the $\mathrm{SSU}{ }^{20,29,30,37}$. During translocation on non-slippery mRNA, the $\mathrm{CHI}$ state is too transient to be captured (Fig. 1c, d). On the slippery mRNA the movement of pept-tRNA ${ }^{\text {Lys }}$ - $\mathrm{Cy} 5$ into $\mathrm{CHI}$ is rapid, but the exit from the $\mathrm{CHI}$ state is delayed due to enduring fluctuations between the $\mathrm{CHI}$ and $\mathrm{P} / \mathrm{P}$ states before completing translocation (Fig. 1e, f).

We then performed analogous experiments using the slippery mRNA and EF-G mutants carrying single amino acid substitutions of residue Q507 at the tip of domain 4, EF-G(Q507A), EF-G(Q507N), and EFG(Q507D) (Fig. 2a). Replacements of Q507 promote -1 frameshifting and the frameshifting efficiency depends on the type of amino acid substitution ${ }^{16}$. With different mutants we again find two ribosome populations, one where tRNAs move rapidly from PRE to POST and another in which tRNAs dwell in transitions between $\mathrm{CHI}$ and $\mathrm{P} / \mathrm{P}$ states before reaching the POST state. The percentage of ribosomes with delayed exit from the $\mathrm{CHI}$ state increases in the order EF-G(Q507A) < EF-G(Q507N) < EF-G(Q507D) (Fig. $2 b-d)$. The variation in the fraction of rapidly translocating ribosome population is not due to ribosome binding defects of EF-G mutants ${ }^{16}$. EF-G wt and all Q507 variants stabilize the $A / P^{*}$ state upon binding to PRE prior to translocation (Supplementary Fig. 2a) and the transitions PRE to the $\mathrm{CHI}$ state are rapid in all 
cases $\left(k_{T L} \geq 30 \mathrm{~s}^{-1}\right.$, Figure 1e). The prevalent fluctuations on the slowly translocating ribosomes are between CHI (FRET 0.4) and P/P (FRET 0.2) states (Fig. 2e, Supplementary Fig. 2b, Table 1). The overall translocation rate on ribosomes delayed in the $\mathrm{CHI}$ state is low $\left(\sim 0.2 \mathrm{~s}^{-1}\right)$ and similar with $\mathrm{EF}-\mathrm{G}(\mathrm{wt})$ and Q507 mutants(Supplementary Fig. 2c, Table 1), which is at least two orders of magnitude slower compared to ribosomes that transit the $\mathrm{CHI}$ state rapidly. Notably, the biochemical frameshifting efficiency (determined in independent experiments by quantitative analysis of peptide products; Supplementary Fig. 3) correlates very well with the slow population among all translocating ribosomes (Fig. $2 b-d, f)$. The slope of the linear regression is close to 1 , suggesting that frameshifting is to a large extent due to the fraction of slow ribosomes. These findings indicate that ribosomes slip into the -1 frame while pept-tRNA is in the $\mathrm{CHI}$ state or upon attempting to move from $\mathrm{CHI}$ to the POST state.

To verify that slowly translocating ribosomes are prone to spontaneous frameshifting, we monitored in the same experiment translocation and aa-tRNA binding to the next A-site codon. We followed translocation of pept-tRNA ${ }^{\text {Lys }}$ labeled by a quencher BHQ2 (pept-tRNA ${ }^{\text {Lys }}$-BHQ2) relative to L11-Cy3

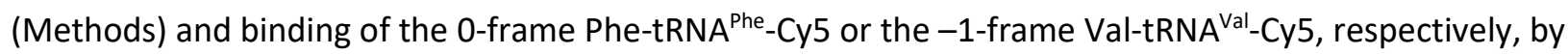
FRET from L11-Cy3 (Fig. 3). Binding of Lys-tRNA ${ }^{\text {Lys }-B H Q 2 ~ t o ~ L 11-C y 3-l a b e l e d ~ P O S T ~ c o m p l e x e s ~ l e a d s ~ t o ~ t h e ~}$ drop of Cy3 fluorescence due to quenching (Supplementary Fig. 4a, b). The resulting PRE1 complex shows fluctuations between two low fluorescence states, presumably $A / A, A / P$ and $A / P^{*}$ conformations (Supplementary Fig. 4b). During translocation on non-slippery mRNA by EF-G(wt) (Fig. 3a-f), PRE1 rapidly (within one frame) converts into POST2, leading to the dequenching of the Cy3 fluorophore (Fig. 3b, e, Supplementary Fig. 4d). When Phe-tRNA ${ }^{\text {Phe }}$-Cy5 complementary to the 0 -frame codon binds to POST2 complexes (Fig. 3b-c), we observe a two-state FRET efficiency change corresponding to codon recognition (CR) and accommodation (AC) of Phe-tRNA ${ }^{\text {Phe }}$ in the A site ${ }^{38}$ forming the PRE2 complex (Fig. 3b-c). PRE2 converts to POST3 due to translocation (Supplementary Fig. 4e; in the example of Fig. 3b,c,

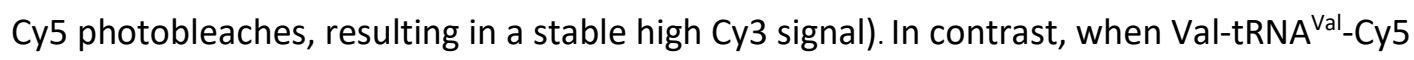
complementary to the -1-frame codon is added to POST2 complexes, we observe only short-lived FRET signals (Fig. 3e-f), showing Val-tRNA ${ }^{\mathrm{Val}}$ as it makes multiple unsuccessful attempts to read a near-cognate 0 -frame codon ${ }^{38}$. The lack of Val-tRNA accommodation suggests that the ribosome remained in the 0frame. When we carry out the same experiment on slippery mRNA with EF-G(Q507D), pept-tRNA ${ }^{\text {Lys }}$ BHQ2 moves from the PRE1 into a state with intermediate fluorescence intensity between PRE1 and POST2 where it dwells for a long time while making reversible excursions towards the $\mathrm{P} / \mathrm{P}$ before reaching the POST2 state (Fig. 3g-i, Supplementary Fig. 4f), very similar to the dwelling behavior observed with FRET (Fig. 2). After some time, -1-frame Val-tRNA ${ }^{\text {Val }}$-Cy5 is accommodated into POST2 
and then fluctuates between $A / A, A / P$ and $A / P *$ states. Accommodation of Val-tRNA provides a strong evidence that after the delayed translocation the ribosome moved into the -1-frame exposing theVal codon in the A site (Fig. 3h-i).

\section{Translocation of deacylated tRNA on slippery mRNA}

Next, we used smFRET between tRNA ${ }^{\text {Lys }}$-Cy5 in the P site and the ribosomal protein S13 labeled with Cy3 (S13-Cy3) to follow the trajectory of deacylated tRNA movement from the P to the E site (Fig. 4a, b). In the PRE state on non-slippery mRNA, tRNA ${ }^{\text {Lys }}$-Cy5 fluctuates between the P/P (FRET 0.9) and P/E (FRET 0.6) states (Supplementary Fig. 5). Upon addition of EF-G, tRNA ${ }^{\text {Lys }}-$ Cy5 moves rapidly $\left(k_{T L} \geq 30 s^{-1}\right)$ from $P / P$ or P/E into a FRET 0.3 state followed by the loss of FRET (Fig. 4c, d). We assign FRET 0.3 to the transient occupancy of the E site by deacylated tRNA; the subsequent transition to FRET 0 reflects the dissociation from the ribosome (Fig. 4a, Supplementary Fig. 6a). The overall reaction of tRNA translocation and dissociation is rapid ( $k_{\text {off }}=1 \mathrm{~s}^{-1}$, Fig. $3 \mathrm{~b}-\mathrm{d}$, Table 2$)$, in agreement with previous reports ${ }^{23,26}$. Surprisingly, we observed the same translocation pattern on slippery and non-slippery mRNA with rapid transition of tRNA ${ }^{\text {Lys }}$-Cy5 to $\mathrm{CHI}$ followed by dissociation from the ribosome (Fig. 4d inset, Supplementary Fig. 6b, d, Table 2). Moreover, translocation with EF-G(wt) is not different from that with EF-G(Q507D), the mutant promoting the highest frameshifting efficiency and resulting in the lowest ensemble pept-tRNA translocation rate ${ }^{16,17}$ (Fig. 4e, f, Supplementary Fig. 6c, d, Table 2). In all cases, translocation of deacylated tRNA is fast, directional and irreversible. Notably, on ribosomes where pept-tRNA translocates slowly, translocation and subsequent dissociation of deacylated tRNA is much faster than the movement of pepttRNA (Tables 1 and 2), i.e. translocation of pept-tRNA from the $A$ to the $P$ site is not completed when deacylated tRNA has already cleared the $E$ site. This indicates that movements of pept-tRNA are uncoupled from the displacement of deacylated tRNA on the fraction of ribosomes that undergo frameshifting, allowing pept-tRNA to more easily access the -1-frame codon after the E-site tRNA release.

\section{Identification of key transitions leading to frameshifting}

To further narrow down the timing of spontaneous -1 frameshifting, we studied translocation on slippery mRNA in the presence of EF-G(wt) and GTP GTPases with similar affinity and orientation as GTP 39 . Ensemble translocation rates are reduced by approximately 30-fold by replacing GTP with GTPYS, because tRNAs are trapped at early steps of 
translocation (Fig. 5a) 20, 23, 40,41. Although translocation rates with EF-G(wt)-GTPyS and EF-G(Q507D)-GTP are similar ${ }^{16,17}$, the frameshifting efficiency on slippery mRNA is much lower than with EF-G(Q507D)-GTP, and is similar to that with EF-G(wt)-GTP (Fig. 5a). This result indicates that slow translocation alone does not explain the high frameshifting efficiency, which prompted us to analyze the pept-tRNA translocation trajectories in the presence of GTPYS (Fig. 5b-h). GTP $\gamma S$ did not affect the ability of EF-G to stabilize pepttRNA in the A/P* state (Supplementary Fig. 7a). The majority of traces $(73 \%)$ shows slow translocation while sampling the FRET 0.4 state (Figure 5b, c, Table 1), which may be an authentic $\mathrm{CHI}$ or a CHI-like offpathway state. Pept-tRNA fluctuates predominantly between $\mathrm{A} / \mathrm{P}^{*}$ and $\mathrm{CHI}$, rather than between $\mathrm{CHI}$ and P/P states as observed with EF-G-GTP on slippery mRNA on the fraction of slow ribosomes (Fig. 5d, Supplementary Fig. 7b). The overall pept-tRNA translocation rate on a slippery mRNA is $\sim 0.2 \mathrm{~s}^{-1}$ (Table 1), similar to that measured with GTPYS on a non-slippery sequence, $0.17 \mathrm{~s}^{120}$. Notably, also translocation of deacylated tRNA ${ }^{\text {Lys }}$-Cy5 is slow (0.2-0.3 s $\mathrm{s}^{-1}$; Fig. 5e, f, Supplementary Fig. 7c, Tables 1 and 2), indicating synchronous displacement of the two tRNAs in the presence of EF-G-GTPyS. Deacylated tRNA dwells mostly in the $E$ site, which may prevent the pept-tRNA from sampling the -1-frame codon and would explain why the reading frame is maintained.

We then used the antibiotic spectinomycin $(\mathrm{Spc})$ as alternative method to stall translocation at an early stage (Fig. 5a, Supplementary Fig. 8) ${ }^{26,32}$. Spc binds to h34 of 16S rRNA connecting the head and the body domain of the $\mathrm{SSU}^{32,42}$. Our smFRET translocation experiments show that the effect of Spc is similar to that of EF-G-GTPyS: pept-tRNA fluctuates between $\mathrm{A} / \mathrm{P}^{*}$ and a $\mathrm{CHI}$-like state, whereas deacylated tRNA dwell time in the E site is prolonged; both tRNAs do not proceed to POST states and the efficiency of -1 frameshifting is low (Fig. 5a, Supplementary Fig. 8). These results suggest that although Spc binding to the ribosome does not affect GTP hydrolysis by EF-G, Spc blocks the conformational rearrangements that couple GTP hydrolysis and Pi release to tRNA movement. With respect to the mechanism of -1 frameshifting, these findings indicate that spontaneous ribosome slippage occurs with pept-tRNA in $\mathrm{CHI}$ state or attempting to move from $\mathrm{CHI}$ to the POST state, whereas deacylated tRNA has been released from the ribosome.

\section{Movements of SSU head domain during translocation on slippery mRNA}

To test the potential effect of ribosome dynamics, we monitored the SSU head domain movements using a validated FRET pair with labels on the SSU protein S13 (S13-Cy3) and the LSU protein L33 (L33-Cy5) (Fig. 
$6 a)^{23,34}$. On PRE complexes in the absence of EF-G, we observe two interconverting states with FRET 0.5 and 0.8, respectively, corresponding to non-rotated $(\mathrm{N})$ and rotated-swiveled $(\mathrm{S})$ states of the SSU head domain (Supplementary Fig. 9a-d). POST complexes are predominantly in the FRET 0.5 (N) state (Supplementary Fig. 9e-g). After addition of EF-G to PRE complexes, the majority of ribosomes transiently populate the $\mathrm{S}$ state before adopting a long-lived N (POST) state ( $85 \%$ on non-slippery and $87 \%$ on slippery mRNA; Figure 6b, Supplementary Fig. 10a). Notably, back swiveling of the SSU head domain in the presence of EF-G occurs at a rate similar to that on PRE complexes in the absence of EF-G (Suplementary Figs. 9d, 10b and Table 3), indicating that back swiveling may occur spontaneously after EF-G dissociation from the ribosome. The transition rates from the last $\mathrm{S}$ to long-lived $\mathrm{N}$ state are similar on non-slippery and slippery mRNA in the presence of EF-G(wt) (Supplementary Fig. 10b and Table 3) and agree with rates measured in previous ensemble and smFRET experiments ${ }^{16,17,23,26,28}$. The minor population of complexes (15\% on non-slippery mRNA and $13 \%$ on slippery mRNA) stayed in the $\mathrm{S}$ state and did not reach the $\mathrm{N}$ state during the time of the experiment.

When we induced translocation on slippery mRNA by EF-G(Q507D), the ratio of ribosomes showing fast and slow back swiveling is inversed ( $13 \%$ fast and $87 \%$ slow, Fig. $6 \mathrm{~b}, \mathrm{~d}$ ). Notably, similar fractions of ribosomes show slow backward swiveling (Fig. 6d) and slow pept-tRNA translocation (Fig. 2d). The rate of SSU head domain closure $\left(<0.1 \mathrm{~s}^{-1}\right.$; Supplementary Fig. $10 \mathrm{c}$ and Table 3$)$ is lower than that of pept-tRNA translocation ( $0.3 \mathrm{~s}^{-1}$; Table 1$)$ or the dissociation of deacylated tRNA from the ribosome $\left(0.6 \mathrm{~s}^{-1}\right.$; Table 2), suggesting that pept-tRNA continues to fluctuate between $\mathrm{CHI}$ and P/P states because the SSU remains in a swiveled conformation, while deacylated tRNA dissociates from the ribosome. It is important to note that, in contrast to the swiveling motion of the SSU head domain, the rotational movement of the SSU body domain with respect to the LSU most likely does not contribute appreciably to spontaneous frameshifting, as both forward and backward SSU body rotation precede the formation of the $\mathrm{CHI}$ state ${ }^{19}$, 23, 31, 43. In summary, our data show that slow translocation by EF-G(Q507D) stalls the SSU head domain in the swiveled state which renders ribosomes susceptible to spontaneous frameshifting due to delayed relockingof pept-tRNA in the P site. 


\section{Discussion}

Choreography of translocation on a slippery mRNA. The present data show how slippery sequences affect the choreography of translocation and how this leads to frameshifting. While on the non-slippery mRNA all ribosomes behave in a quasi-uniform way (within the time resolution of TIRF experiments) and translocate rapidly, on a slippery mRNA we identify two distinct ribosome populations, one that translocates rapidly, and another that is very slow in completing pept-tRNA translocation (Fig. 7a,b). The fraction of such slow ribosomes in the population correlates with the frameshifting efficiency and slow translocation preceeds incorporation of the -1-frame tRNA. On slow ribosomes, both tRNAs rapidly move from the $A / P$ or $A / P^{*}$ and $P / E$ into their respective $C H I$ states. Deacylated tRNA is then rapidly released from the ribosome. Normally, pept-tRNA becomes locked in the P site upon backward movement of the SSU head domain. On the slippery sequence, the locking is delayed and pept-tRNA fluctuates between $\mathrm{CHI}$ and $\mathrm{P} / \mathrm{P}$ states. If base pairing of the pept-tRNA anticodon with the -1-frame codon is favored over the 0 frame codon, as is often the case with slippery sequences ${ }^{15}$, these continuing fluctuations provide the time window for pept-tRNA to switch to the -1-frame.

Residues at the tip of EF-G domain 4, in particular Q507, are important for reading frame maintenance ${ }^{16,17}$. Recent cryo-EM structure suggests that in the $A / P$ or $A / P^{*}$ state, EF-G domain 4 is flexible and most probably not involved in the stabilization of the codon-anticodon complex in the A site 19. The codon-anticodon duplex is supported by the interactions with the residues of 16S rRNA h44 in the SSU body domain ${ }^{19,31}$. Upon moving to the $\mathrm{CHI}$ state, the contacts with the SSU body domain are disrupted and tRNA anticodon has a propensity to disconnect from its 0 -frame codon ${ }^{18,30}$. EF-G residues at the tip of domain 4 stabilize the codon-anticodon duplex in its correct geometry, thereby contributing to the reading frame maintenance ${ }^{18}$.

The timing of events during spontaneous frameshifting shows similarities but also differences to -1 programmed ribosome frameshifting $(-1 P R F)^{44}$. A hallmark of $-1 P R F$ is the slowing down of translocation at the slippery site facilitated by mRNA secondary structures, such as downstream stem loops or pseudoknots. During stalling, the SSU head domain is swiveled ${ }^{45}$ and the SSU body is rotated with respect to the LSU ${ }^{46,47}$, suggesting a key role of SSU dynamics both in programmed and spontaneous -1 frameshifting. Single molecule studies of -1PRF on E. coli dnaX mRNA using optical tweezers showed that stalled ribosomes make multiple translocation attempts sampling sequences upstream or downstream of the 0 frame ${ }^{48}$. In our study, fluctuations of pept-tRNA between $\mathrm{CHI}$ and P/P states allow ribosomes to explore alternative reading frames and eventually re-equilibrate in a reading frame that is 
thermodynamically favored before resuming translation. The difference between the spontaneous slippage and-1PRF concerns the timing of deacylated tRNA release, which is rapid during spontaneous frameshifting (this paper and ${ }^{16}$ ), but slow in the two examples of -1PRF where this was studied ${ }^{45,49}$. Thus, frameshifting can occur both with one or two tRNAs bound, provided pept-tRNA is trapped in fluctuations between $\mathrm{CHI}$ and P/P. Frameshifting can be also induced by the lack of the A-site tRNA, resulting in a 'hungry' frameshifting ${ }^{50}$, which is also a slow process, but which proceeds via a different mechanism presumably involving spontaneous P-site tRNA slippage, rather than A-site tRNA translocation.

Slow gears of translocation. Our results describe two alternative translocation pathways, one that ensures rapid coordinated movement of tRNAs in the correct reading frame, and the other which is slow and prone to -1 frameshifting (Fig. 7b). Recent force and fluorescence measurements suggested that ribosomes can operate in two alternative (fast and slow) gears during translation in response to the mechanical barrier of an mRNA hairpin ${ }^{51}$. In this slow gear, unwinding of the hairpin occurred during forward rotation of the SSU head domain suggesting that delays in steps preceeding tRNA movement into the $\mathrm{CHI}$ state accounted for the reduction of the overall translation speed. Ribosomes proceed in reversible sub-codon steps against the obstacle, suggesting that they exploit fluctuations on the mRNA to overcome the mechanical barrier. Our data show tRNA fluctuations between early translocation states when we replace GTP with GTP $\gamma$ S and in the presence of the antibiotic Spc, but these fluctuations do not increase frameshifting. Thus, it appears that there are different ways for the ribosome to switch gears, but frameshifting is promoted only at a particular step when pept-tRNA transits from CHI to P/P (Fig. 7b).

Our experiments show that at given translocation conditions, some ribosomes in a population take a fast route, whereas others switch into a slow mode. Previous molecular dynamics simulations revealed almost 500,000,000 possible kinetic sequences of intermediate states during translocation and calculated the favoured route of tRNA movement ${ }^{52}$. Apparently, specific mRNA sequences can set the course for ribosomes to deviate from the designated route and change into alternative pathways ( ${ }^{51}$ and our study). Thus, the sequence of the mRNA appears to modulate the pace of translation not only by posing a steric hindrance for the ribosome moving along the mRNA, but also in more subtle ways that may link specific mRNA sequences with alternative translocation outcomes. The structural basis as to why the ribosomes switch to the slow gear and the physiological importance of this switch for biological processes, such as the nascent protein folding or maintenance of the mRNA stability by ribosome loading, remains to be elucidated in the future work. 


\section{Materials \& Methods}

All experiments were carried out in $\mathrm{TAKM}_{7}\left(50 \mathrm{mM}\right.$ Tris- $\mathrm{HCl}, \mathrm{pH} 7.5$ at room temperature, $70 \mathrm{mM} \mathrm{NH}_{4} \mathrm{Cl}$, $30 \mathrm{mM} \mathrm{KCl}$, and $7 \mathrm{mM} \mathrm{MgCl}_{2}$ ) at $22^{\circ} \mathrm{C}$, unless stated otherwise.

Ribosomes from E. coli, $\mathrm{f}\left[{ }^{3} \mathrm{H}\right]$ Met-tRNA ${ }^{\mathrm{fMet}},\left[{ }^{14} \mathrm{C}\right] \mathrm{Gly}$-tRNA ${ }^{\mathrm{Gly}},\left[{ }^{14} \mathrm{C}\right] \mathrm{Ala}$-tRNA ${ }^{\text {Ala }}$, Lys-tRNA ${ }^{\text {Lys }}$, Phe-tRNA ${ }^{\text {Phe }}$, ValtRNA ${ }^{\mathrm{Val}},\left[{ }^{14} \mathrm{C}\right]$ Lys-tRNA ${ }^{\text {Lys }}$-Cy5, initiation factors, and EF-Tu were prepared as described ${ }^{36,53,54} \cdot\left[{ }^{14} \mathrm{C}\right] \mathrm{Gly}$ tRNA ${ }^{\text {Gly }}$ was prepared from $E$. coli total tRNA by selective aminoacylation of tRNA ${ }^{\text {Gly }}$ with $\left[{ }^{14} \mathrm{C}\right]$ Gly followed by isolation of $\left[{ }^{14} \mathrm{C}\right]$ Gly-tRNA ${ }^{\text {Gly }}$ in the ternary complex formed by incubating histidine-tagged EF-Tu (2-fold excess over $\left[{ }^{14} \mathrm{C}\right]$ Gly-tRNA $\left.{ }^{\text {Gly }}\right)$ and GTP $(1 \mathrm{mM})$, in the presence of phosphoenolpyruvate $(3 \mathrm{mM})$ and pyruvate kinase $(0.5 \%)$ in $\mathrm{TAKM}_{7}$ for $15 \mathrm{~min}$ at $37^{\circ} \mathrm{C}$ followed by affinity chromatography using Protino $\mathrm{Ni}$ IDA 2000 Packed Columns (Macherey-Nagel), phenolization and ethanol precipitation of the $\left[{ }^{14} \mathrm{C}\right] \mathrm{Gly}$ tRNA ${ }^{\text {Gly } 55}$. The following mRNAs were synthesized by IBA Lifesciences and Eurofins and used for biochemical and single molecule experiments (0-frame codons are separated by space, slippery sequence is underlined):

5'-biotin-CAACCUAAAACUUACACACCCGGCAAGGAGGUAAAUA AUG GGA AAG UUC AUUACCUAA-3'

5'-biotin-CAACCUAAAACUUACACACCCGGCAAGGAGGUAAAUA AUG UUU AAG UUC AUUACCUAA-3'

5'-biotin-CAACCUAAAACUUACACACCCGGCAAGGAGGUAAAUA AUG GCA AAA AAG UUC AUUACCUAA-3'

5'-biotin-CAACCUAAAACUUACACACCCGGCAAGGAGGUAAAUA AUG GCU AAG AAG UUC AUUACCUAA-3'

\section{Labeling of 705 ribosomes and tRNAs}

$70 S$ ribosomes labeled at protein L11 were prepared as described ${ }^{20}$. Protein L11 was expressed in E. coli BL21(DE3) after induction with isopropyl- $\beta$-D-thiogalactoside (IPTG, $1 \mathrm{mM}$ ). Cells were lysed by sonication in buffer (50 mM HEPES, $10 \mathrm{mM} \mathrm{MgCl}_{2}, 10 \mathrm{mM} \mathrm{NH}_{4} \mathrm{Cl}, 1 \mathrm{mM}$ dithiothreitol, $0.5 \mathrm{mM}$ EDTA, pH 7.2) and inclusion bodies were solubilized in the same buffer containing $6 \mathrm{M}$ urea. The protein was dialyzed against 100 volumes of the same buffer and purified by fast protein liquid chromatography (FPLC) using a HiTrap SP HP column (GE Healthcare) using a linear gradient of $10-500 \mathrm{mM} \mathrm{NH}_{4} \mathrm{Cl}$ in the same buffer with $6 \mathrm{M}$ urea. Labeling of L11 at position C38 was carried out in the same buffer supplemented with $0.5 \mathrm{M} \mathrm{NH}{ }_{4} \mathrm{Cl}$ by adding a 3-fold excess of Cy3-maleimide (GE Healthcare) dissolved in dimethylsulfoxide (DMSO) and incubating for $12 \mathrm{~h}$ at $4^{\circ} \mathrm{C}$. Excess dye was removed on an FLPC HiTrap SP HP column using the same salt gradient as above. To refold labeled L11, the buffer was gradually replaced by 50 mM HEPES, $10 \mathrm{mM}$ $\mathrm{MgCl}_{2}, 300 \mathrm{mM} \mathrm{NH}_{4} \mathrm{Cl}, 1 \mathrm{mM}$ dithiothreitol, $0.5 \mathrm{mM}$ EDTA, pH 7.2, 25\% glycerol using a Vivaspin 5,000 concentrator $^{20}$. Ribosomes lacking protein L11 (70S $\left.\Delta \mathrm{L} 11\right)$ were purified from E. coli AM68 according to 
the standard protocol ${ }^{53}$. Reconstitution of 70S was carried out in $\mathrm{TAKM}_{21}$ buffer by mixing $\triangle \mathrm{L} 11$ 70S with 10 -fold excess of L11-C38-Cy3 and incubation for $45 \mathrm{~min}$ at $45^{\circ} \mathrm{C}$. Purification of 70S-L11-Cy3 from the excess of labeled L11 was performed by centrifugation through sucrose cushion (1.1 M sucrose in $\mathrm{TAKM}_{21}$ ). Pellets were dissolved in $\mathrm{TAKM}_{7}$ and the concentration was determined by absorption at 260 $\mathrm{nm}$.

S13-labeled 70S ribosomes were prepared as described ${ }^{23,34}$. A single-cysteine variant of protein S13 (C85S P112C) was expressed in E. coli BL21(DE3) after induction with IPTG (1 mM). Cells were lysed by sonication in buffer (50 mM HEPES pH 7.5, $150 \mathrm{mM} \mathrm{KCl,} \mathrm{5 \%} \mathrm{glycerol,} 6 \mathrm{mM} \beta$-mercaptoethanol). S13 was in the insoluble fraction and inclusion bodies were dissolved in buffer $(50 \mathrm{mM} \mathrm{HEPES} \mathrm{pH} \mathrm{7.5,} 300 \mathrm{mM} \mathrm{KCl}, 5 \%$ glycerol, $6 \mathrm{mM} \beta$-mercaptoethanol, $8 \mathrm{M}$ urea). Solubilized S13 was diluted in the same buffer without $\mathrm{KCl}$ and purified by FPLC using a HiTrap SP HP column (GE Healthcare) with a linear gradient of 50-1000 mM $\mathrm{KCl}$ in the same buffer with $6 \mathrm{M}$ urea, followed by a Resource $\mathrm{S}$ column with the same $\mathrm{KCl}$ gradient. Cy3labeling of S13 at C112 was carried out in the same buffer supplemented with $0.5 \mathrm{M} \mathrm{NH}_{4} \mathrm{Cl}$ by adding a 3fold excess of Cy3-maleimide (GE Healthcare) dissolved in DMSO and incubating for $2 \mathrm{~h}$ at room temperature. Excess dye was removed on a HiTrap SP HP column using the same salt gradient as above. S13(C112-Cy3) was dialysis into 50 mM HEPES, 20 mM MgCl, $400 \mathrm{mM} \mathrm{KCl,} \mathrm{pH} \mathrm{7.5,} \mathrm{5 \%} \mathrm{glycerol,} 6 \mathrm{mM}$ mercaptoethanol, concentrated and stored at $-80^{\circ} \mathrm{C}$. $30 \mathrm{~S}$ subunits lacking protein S13 (30S $\Delta \mathrm{S} 13$ ) were purified from E. coli $\mathrm{AM}^{23} 8^{23}$. Reconstitution of $30 \mathrm{~S}$ subunits was carried out in $\mathrm{TAKM}_{20}$ buffer by mixing $\triangle \mathrm{S} 1330 \mathrm{~S}$ with 1.5 -fold excess of S13-P112C-Cy3 and incubation at $42^{\circ} \mathrm{C}$ for $30 \mathrm{~min}$. Purification of $30 \mathrm{~S}$ S13-Cy3 from the excess of labeled S13 was performed by centrifugation through a sucrose cushion (0.9 $M$ sucrose in $\mathrm{TAKM}_{21}$ buffer). Pellets were dissolved in $\mathrm{TAKM}_{7}$ and the concentration was determined by absorption at $260 \mathrm{~nm}$.

50 subunits lacking protein L33 (50S $\Delta \mathrm{L} 33$ ) and a single cysteine variant of protein L33 (P31C) were purified and labeled as described ${ }^{23}$. Reconstitution of 50S subunits was carried out in buffer (50 mM HEPES, pH 7.5, $400 \mathrm{mM} \mathrm{KCl}, 20 \mathrm{mM} \mathrm{MgCl}_{2}$ and $6 \mathrm{mM}$ mercaptoethanol) by mixing $\Delta \mathrm{L} 3350 \mathrm{~S}$ with 1.1-fold excess of L33-P31C-Cy5 and incubation for $90 \mathrm{~min}$ at $37^{\circ} \mathrm{C}$. 50S-L33-Cy3 were purified from the excess of labeled L33 by centrifugation through a $0.9 \mathrm{M}$ sucrose cushion in TAKM 21 buffer. Pellets were dissolved in $\mathrm{TAKM}_{7}$ and the concentration was determined by absorption at $260 \mathrm{~nm}$.

Cy5- and BHQ2-labeling at the 3-amino-3-carboxypropyl group at uridine 47 (acp47) of tRNA ${ }^{\text {Lys }}$ was carried out by incubating purified E. coli tRNA ${ }^{\text {Lys }}$ with a 100-fold excess of Cy5- or BHQ2-succinimidylester (GE Healthcare and Biosearch Technologies respectively) in $50 \mathrm{mM} \mathrm{HEPES}, \mathrm{pH} 8.5$, for $4 \mathrm{~h}$ at $37^{\circ} \mathrm{C}$. Excess dye 
was removed by phenol extraction and ethanol precipitation. tRNA ${ }^{\text {Lys }}$ (acp47-Cy5 or -BHQ2) was aminoacylated, purified by phenol extraction and ethanol precipitation and additionally by HPLC ${ }^{20,54}$.

\section{Frameshifting assay}

To form initiation complex (IC), 70S ribosomes were incubated with a 3-fold excess of mRNA, initiation factors and $\mathrm{f}\left[{ }^{3} \mathrm{H}\right]$ Met-tRNA ${ }^{\mathrm{fMet}}$ and $1 \mathrm{mM}$ GTP for $30 \mathrm{~min}$ at $37^{\circ} \mathrm{C}$. Complexes were purified by centrifugation through a $1.1 \mathrm{M}(40 \%)$ sucrose cushion in $\mathrm{TAKM}_{21}$ buffer $\left(50 \mathrm{mM}\right.$ tris- $\mathrm{HCl} \mathrm{pH} 7.5$ at $37^{\circ} \mathrm{C}, 70$ $\mathrm{mM} \mathrm{NH}_{4} \mathrm{Cl}, 30 \mathrm{mM} \mathrm{KCl}$, and $21 \mathrm{mM} \mathrm{MgCl}_{2}$ ). Pellets were dissolved in $\mathrm{TAKM}_{7}$ buffer and the concentration of purified complexes was determined by scintillation counting of $\mathrm{f}\left[{ }^{3} \mathrm{H}\right]$ Met radioactivity. Ternary complex was prepared by incubating EF-Tu (3-fold excess over total tRNAs) with $1 \mathrm{mM}$ GTP, 3 mM phosphoenolpyruvate, and $0.5 \%$ pyruvate kinase for $15 \mathrm{~min}$ at $37^{\circ} \mathrm{C}$ and subsequent addition of aminoacyl-tRNAs (5-fold excess to 70S) cognate to the mRNA coding sequence in 0 and -1 frame.

Translation was carried out by incubating purified initiation complex $(0.1 \mu \mathrm{M})$, ternary complexes (5-fold excess over IC) and EF-G $(1 \mu \mathrm{M})$ with GTP or GTP $\gamma \mathrm{S}(1 \mathrm{mM})$ at $22^{\circ} \mathrm{C}$ or $37^{\circ} \mathrm{C}$ for 2 min. Reaction was then quenched with $\mathrm{KOH}(0.5 \mathrm{M})$. The peptides were released by hydrolysis at $37^{\circ} \mathrm{C}$ for 30 min, neutralized by adding $1 / 10$ volume of glacial $100 \%$ acetic acid and analyzed by reversed-phase high performance liquid chromatography (LiChrospher 100 RP-8 HPLC column, Merck) using a 0 to $65 \%$ acetonitrile gradient in $0.1 \%$ trifluoroacetic acid, as described ${ }^{16}$. The 0 - and -1 -frame products were quantified by scintillation counting according to $f\left[{ }^{3} \mathrm{H}\right]$ Met-tRNA ${ }^{\mathrm{fMet}}$ and $\left[{ }^{14} \mathrm{C}\right] \mathrm{Gly}$-tRNA ${ }^{\mathrm{Gly}}$ or $\left[{ }^{14} \mathrm{C}\right] \mathrm{Ala}$-tRNA ${ }^{\text {Ala }}$ radioactivity labels.

\section{Ribosome complexes for smFRET experiments}

IC and TC were prepared as described above. IC $(1 \mu \mathrm{M})$, TC containing $\left[{ }^{14} \mathrm{C}\right] \mathrm{Gly}$-tRNA ${ }^{\mathrm{Gly}}$ or $\left[{ }^{14} \mathrm{C}\right] \mathrm{Phe}-\mathrm{tRNA}{ }^{\mathrm{Phe}}$ $(10 \mu \mathrm{M})(5 \mu \mathrm{M})$ and EF-G-GTP $(1 \mu \mathrm{M})$ were mixed and incubated for $5 \mathrm{~min}$ at $37^{\circ} \mathrm{C}$. The resulting POST complexes were purified by centrifugation through a $1.1 \mathrm{M}$ sucrose cushion in TAKM ${ }_{21}$, the pellet was dissolved in $\mathrm{TAKM}_{7}$ and the concentration was determined by $\left[{ }^{14} \mathrm{C}\right]$ Gly or $\left[{ }^{14} \mathrm{C}\right]$ Phe scintillation counting.

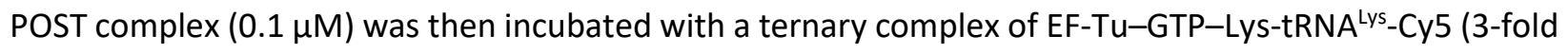
excess) in $\mathrm{TAKM}_{7}$ for $5 \mathrm{~min}$ at $37^{\circ} \mathrm{C}$ to generate the PRE complex carrying fMGK-tRNA ${ }^{\text {Lys }}$-Cy5 or fMFKtRNA ${ }^{\text {Lys }}$-Cy5 in the A site and tRNA ${ }^{\text {Gly }}$ or tRNA ${ }^{\text {Phe }}$ in the P site. The same procedure was followed to prepare 
PRE complexes with $f M G K-t R N A^{\text {Lys }}-B H Q 2$ or $f M F K-t R N A^{\text {Lys }}$-BHQ2. The PRE complex was immobilized in the coverslip as described below.

To prepare POST complexes carrying S13-Cy3 and fMA-tRNA ${ }^{\text {Ala }}$ in the P site, 30S S13-Cy3 $(2 \mu \mathrm{M})$ were incubated in $\mathrm{TAKM}_{20}$ at $37^{\circ} \mathrm{C}$ for $30 \mathrm{~min}$ and used to prepare initiation complexes as described above (50S in 1.5-fold excess over 30S, IFs, mRNA and $\left[{ }^{3} \mathrm{H}\right] \mathrm{fMet}$-tRNA ${ }^{\mathrm{fMet}}$ in 3-fold excess over $30 \mathrm{~S}$ subunits). Ternary complexes were prepared as above using $\left[{ }^{14} \mathrm{C}\right]$ Ala-tRNA ${ }^{\text {Ala }}(10 \mu \mathrm{M})$. IC $(1 \mu \mathrm{M})$, TC $(5 \mu \mathrm{M})$ and EF-G-GTP $(1$ $\mu \mathrm{M}$ ) were mixed together and incubated for $5 \mathrm{~min}$ at $37^{\circ} \mathrm{C}$. The POST complexes were purified by centrifugation through a $1.1 \mathrm{M}$ sucrose cushion in $\mathrm{TAKM}_{21}$, dissolved in $\mathrm{TAKM}_{7}$ and the concentration was determined by $\left[{ }^{14} \mathrm{C}\right]$ Ala radioactivity scintillation counting. POST complex $(0.1 \mu \mathrm{M})$ was then mixed with 3-fold excess of EF-Tu-Lys-tRNA ${ }^{\text {Lys }}$-Cy5-GTP and EF-G-GTP $(0.5 \mu \mathrm{M})$ and incubated at $37^{\circ} \mathrm{C}$ for $5 \mathrm{~min}$ to generate the POST fMAK complex. The POST complex was immobilized on the cover slip as described below and excess of TC and EF-G was washed away. EF-Tu-GTP-Lys-tRNA ${ }^{\text {Lys }}$ was added to the flow chamber to generate the PRE complex carrying fMAKK-tRNA ${ }^{\text {Lys }}$ in the A site and tRNA ${ }^{\text {Lys }}$-Cy5 in the P site.

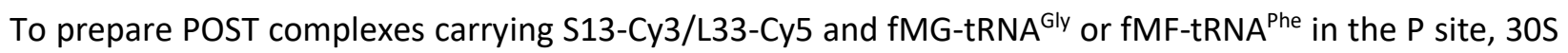
S13-Cy3 were incubated in $\mathrm{TAKM}_{20}$ at $37^{\circ} \mathrm{C}$ for $30 \mathrm{~min}$ and used to form initiation complexes as described above (50S-L33-Cy5 in 1.5-fold excess over 30S subunits). Ternary complexes were prepared as above using $\left[{ }^{14} \mathrm{C}\right]$ Gly-tRNA ${ }^{\text {Gly }}$ or $\left[{ }^{14} \mathrm{C}\right]$ Phe-tRNA ${ }^{\text {Phe }}$. IC $(1 \mu \mathrm{M}), \mathrm{TC}(5 \mu \mathrm{M})$ and EF-G-GTP $(1 \mu \mathrm{M})$ were mixed together and incubated for $5 \mathrm{~min}$ at $37^{\circ} \mathrm{C}$. The POST complexes were purified by centrifugation through a $1.1 \mathrm{M}$ sucrose cushion in $\mathrm{TAKM}_{21}$, dissolved in $\mathrm{TAKM}_{7}$ and the concentration was determined by $\left[{ }^{14} \mathrm{C}\right] \mathrm{Gly}$ or $\left[{ }^{14} \mathrm{C}\right]$ Phe radioactivity scintillation counting, respectively. POST complex $(0.1 \mu \mathrm{M})$ was then mixed with 3fold excess of EF-Tu-Lys-tRNA Lys - GTP and incubated at $37^{\circ} \mathrm{C}$ for 5 min to generate the PRE complex carrying $f M G K-t R N A^{\text {Lys }}$ or fMFK-tRNA ${ }^{\text {Lys }}$ in the $A$ site and tRNA ${ }^{G l y}$ or or RRNA $^{\text {Phe }}$ in the P site. The PRE complex was immobilized in the coverslip as described below.

\section{Cover slip preparation}

Cover slips and objective slides were sonicated in $1 \mathrm{M} \mathrm{KOH}$ for $10 \mathrm{~min}$, cleaned in plasma cleaner (FEMTO plasma cleaner, Diener Electronic $\mathrm{GmbH}$ ), silanized in $3.9 \mathrm{mM}$ N1-[3-(trimethoxysilyl)propyl] diethylenetriamine (Sigma-Aldrich) and $1.7 \mathrm{mM}$ acetic acid for $5 \mathrm{~min}$ and baked for $20 \mathrm{~min}$ at $110^{\circ} \mathrm{C}$. They were covered with 20 mM PEG-NHS (MeO-PEG-NHS, IRIS Biotech GmbH, PEG1165), 0.2 mM Biotin-PEGNHS (IRIS Biotech $\mathrm{GmbH}, \mathrm{PEG1057)}$ in $100 \mathrm{mM} \mathrm{H}_{3} \mathrm{BO}_{3}$ for $1 \mathrm{~h}$ at room temperature, washed with $\mathrm{H}_{2} \mathrm{O}$ to 
remove excess of PEG, dried at $50^{\circ} \mathrm{C}$ and stored under vacuum. Flow chambers were assembled by attaching cover slips on objective slides with double-sided sticky tape.

\section{Sample preparation and TIRF microscopy}

Purified ribosome complexes $(0.1 \mu \mathrm{M})$ were diluted to $1 \mathrm{nM}$ in buffer (TAKM 7 complemented with $8 \mathrm{mM}$ putrescine and $1 \mathrm{mM}$ spermidine). Flow chambers were incubated for $5 \mathrm{~min}$ at room temperature with the same buffer containing additionally $10 \mathrm{mg} / \mathrm{ml} \mathrm{BSA}$ and $1 \mathrm{mM}$ neutravidin (Thermo Scientific) for 5 min. Neutravidin was removed by washing the flow chamber with 5-fold volume excess of the same buffer containing $1 \mathrm{mg} / \mathrm{ml} \mathrm{BSA}$. Ribosome complexes were added to the flow chamber and incubated for $5 \mathrm{~min}$ to immobilize the ribosomes on the surface through the mRNA-biotin-neutravidin interaction. Images were recorded after the addition of imaging buffer to the sample (same buffer with $2.5 \mathrm{mM}$ protocatechuic acid, $50 \mathrm{nM}$ protocatechuate-3,4-dioxygenase (Pseudomonas- Sigma-Aldrich), $1 \mathrm{mM}$ Trolox (6-hydroxy2,5,7,8-tetramethylchromane-2-carboxylic acid) and $1 \mathrm{mM}$ methylviologen (SigmaAldrich)). Cy3 and Cy5 fluorescence time courses during translocation were obtained by adding $0.1 \mu \mathrm{M}$ EF-G and $1 \mathrm{mM}$ GTP or GTPYS to the imaging buffer. In the experiment with tRNA ${ }^{\text {Lys }}$ BHQ2, the imaging

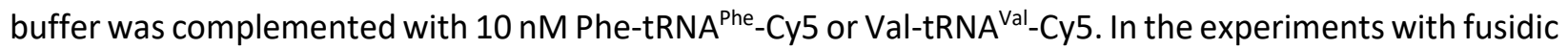
acid and puromycin, $200 \mu \mathrm{M}$ fusidic acid and $1 \mathrm{mM}$ puromycin were added to the diluted sample and imaging buffer, respectively. TIRF imaging was performed on an IX 81 inverted microscope using a PLAPON 601.45 numerical aperture objective (Olympus, Japan). Cy3 fluorescence was excited by a $561 \mathrm{~nm}$ solidstate laser, $25 \mathrm{~mW}$. Images were recorded with an electron multiplying charge-coupled device (em-CCD) camera (CCD-C9100-13, Hamamatsu, Japan). Color channels were separated by projecting donor and acceptor emission on different parts of the CCD chip using an image splitter (dual view micro imager DV2, Photometrics, USA), filter specifications HQ 605/40, HQ 680/30 (Chroma Technology). For most experiments, movies were recorded at a rate of 30.3 frames per second ( $33 \mathrm{~ms}$ per frame). Movies were recorded at a rate of 10 frame per second (100 ms per frame) in the experiment using S13-L33 FRET and EF-G(Q507D).

\section{Data analysis}

Fluorescence time courses for donor (Cy3) and acceptor (Cy5) were extracted using custom-made Matlab (MathWorks) software according to published protocols ${ }^{20}$. A semi-automated algorithm (Matlab) was 
used to select anti-correlated fluorescence traces exhibiting characteristic single fluorophore intensities ${ }^{20}$. The bleed-through of Cy3 signal into the Cy5 channel was corrected using an experimentally determined coefficient of 0.13 . The FRET efficiency was defined as the ratio of the measured emission fluorescence intensities, $\mathrm{Fl}_{\mathrm{Cy} 5} /\left(\mathrm{Fl}_{\mathrm{Cy} 3}+\mathrm{FI}_{\mathrm{cy} 5}\right)$. Trajectories were truncated to remove photobleaching and photoblinking events. Trajectories of smFRET were fitted by Hidden Markov model using the vbFRET software package (http://vbfret.sourceforge.net/) ${ }^{56}$. Two-dimensional contour plots were generated from raw timeresolved FRET trajectories using a custom-made software. The set of all FRET traces for a given complex was compiled in a histogram, which was fitted to a sum of Gaussian functions. Matlab code using an unconstrained nonlinear minimization procedure (fminsearch, Matlab, R2011b) yields mean values and s.d. for the distribution of FRET states. For the experiments with EF-G, FRET traces were post synchronized relative to the first transition to FRET $\leq 0.1$ than the lowest value of the PRE state in each FRET pair, if not stated otherwise. FRET changes in idealized trajectories that were smaller than the s.d. of the Gaussian distribution of the FRET states were not considered as transitions because they were not distinguished from the noise. Dwell times of different FRET states of fluctuating traces were extracted from idealized trajectories. The dwell time histogram for each transition was fitted to an exponential function, $y=y_{0}+A e^{-}$

${ }^{t / \tau}$. Rates $(k)$ were calculated by taking the inverse of dwell times $(\tau)$. The observed rates were corrected according to $k_{\text {corrected }}=k_{\text {observed }}-k_{\text {photobleach }}-1 / T$, where $T$ observation time (33 s for most experiments, $100 \mathrm{~s}$ for S13-L33/EF-G(Q507D) experiment), $k_{\text {photobleach }}=0.03 \pm 0.01 \mathrm{~s}^{-1}$.

\section{$\underline{\text { Acknowledgements }}$}

We thank F. Peske for helpful discussions, B.-Z. Peng for providing the EF-G mutants, R. Belardinelli for labeled LSU, T. Senyushkina and J. C. Thiele for help with coding. We thank O. Geintzer, V. Herold, T. Hübner, S. Kappler, M. Klein, C. Kothe, A. Pfeiffer, T. Steiger and M. Zimmermann for expert technical assistance. The work was supported by the German research council (Deutsche Forschungsgemeinschaft) with project grants to M.V.R. (SFB860, project A3) and S.A. (SFB860, project A15). P.P. acknowledges an Onassis Foundation Scholarship.

\section{Author Contributions}

P.P. and A.P. performed experiments and data analysis. P.P., M.V.R. and S.A. designed experiments, interpreted the data and wrote the paper. 


\section{Competing Interests}

The authors declare no competing financial interests.

Data availability

Data are available from the corresponding authors upon reasonable request.

Code availability

The code used to analyze data is available from the corresponding authors upon reasonable request. 


\section{Main Text Figures}

a

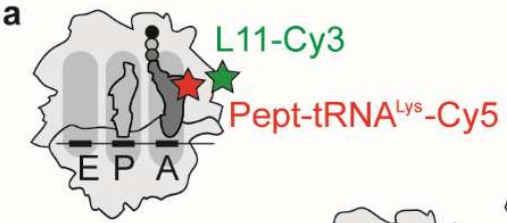

$\operatorname{PRE}(\mathrm{A} / \mathrm{A}, \mathrm{A} / \mathrm{P})$

FRET 0.8

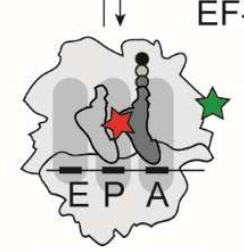

$\operatorname{PRE}\left(\mathrm{A} / \mathrm{P}^{*}\right)$

FRET 0.6
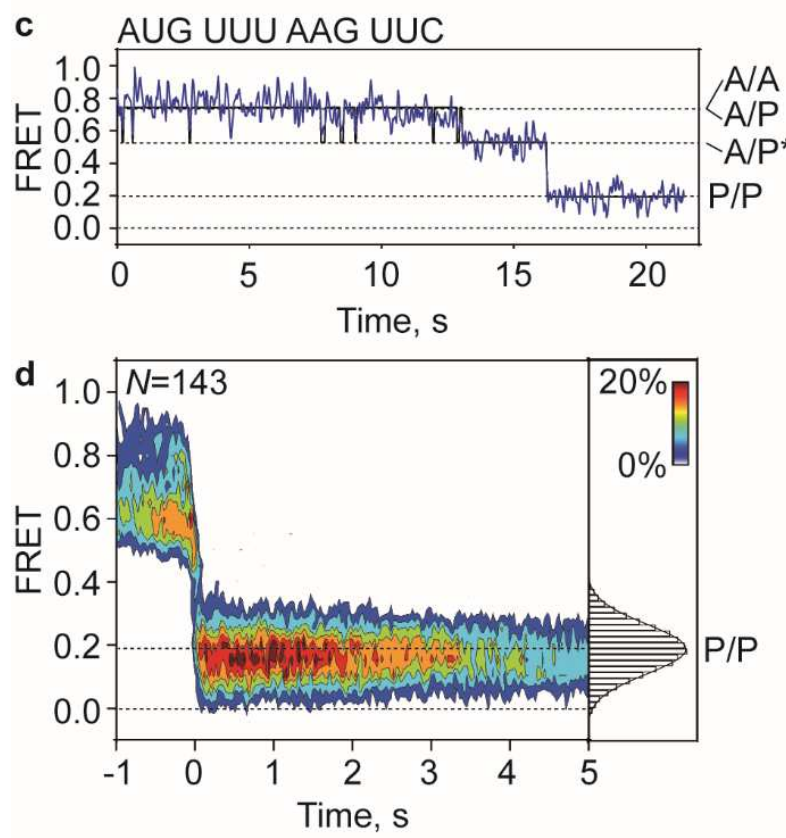

b Slippery mRNA

$$
\frac{\frac{f M}{A U G} \frac{G}{G G A} \frac{K}{A A G} \frac{F}{U U C}}{K} \frac{0 \text { frame }}{V}-1 \text { frame }
$$

Non-slippery mRNA

$\frac{f M}{A U G} \frac{F}{U U U} \frac{K}{A A G} \frac{F}{U U C} 0$ frame e
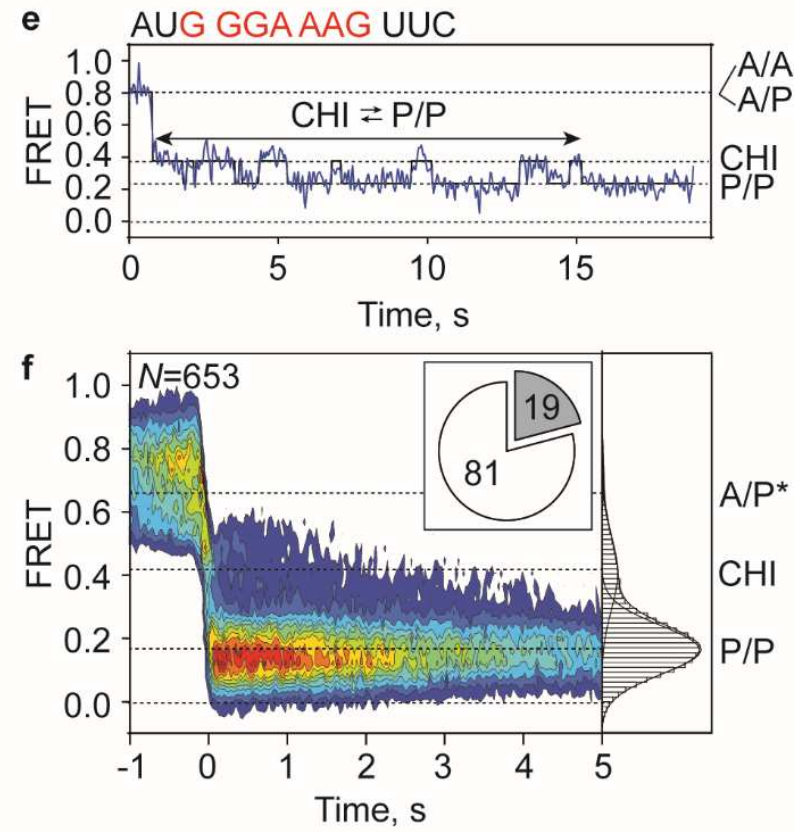

Figure 1. EF-G-induced translocation of pept-tRNA.

(a) Schematic of the smFRET experiment. fMet-Gly-Lys-tRNA ${ }^{\text {Lys }-C y 5}$ (pept-tRNA ${ }^{\text {Lys }}$-Cy5; red star) fluctuates between classical $A / A$ and hybrid $A / P$ and $A / P *$ states in the absence of EF-G. Upon EF-G addition, pept-tRNA moves into a transient $\mathrm{CHI}$ state before reaching the $\mathrm{P} / \mathrm{P}$ state. The movement is monitored by change in FRET between pept-tRNA ${ }^{\text {Lys }}$-Cy5 to the protein L11 labeled with Cy3 (L11-Cy3; green star). FRET values are assigned to PRE and POST states in independent experiments (Supplementary Fig. 1) and validated by distance measurements based on cryo-EM structures ${ }^{19,31,32}$.

(b) Coding sequences of mRNA constructs. Slippery sequence encodes fMet-Gly-Lys-Phe peptide in 0 frame and fMet-Gly-Lys-Val in -1 frame. Non-slippery mRNA that does not support frameshifting encodes only the 0 -frame peptide fMet-Phe-Lys-Phe. 
(c) Representative smFRET time trace showing tRNA translocation on non-slippery mRNA. Trace shows fluctuations between FRET $0.8(\mathrm{~A} / \mathrm{A}, \mathrm{A} / \mathrm{P})$ and $0.6\left(\mathrm{~A} / \mathrm{P}^{*}\right)$ followed by rapid transition to FRET $0.2(\mathrm{P} / \mathrm{P})$. Black line shows here and in all SmFRET traces the HMM fit of the data.

(d) Contour plot showing distribution of FRET values during tRNA translocation on non-slippery mRNA. Transitions occur from either $\mathrm{A} / \mathrm{A}$ and $\mathrm{A} / \mathrm{P}$ or $\mathrm{A} / \mathrm{P}^{*}$ to $\mathrm{P} / \mathrm{P}$ in less than $33 \mathrm{~ms}$. Traces are synchronized to the first transition below FRET 0.5. Histogram at the right shows distribution of FRET values after synchronization. Data are from 5 independent experiments $(\mathrm{N}=5)$.

(e) Representative smFRET time trace showing tRNA translocation on slippery mRNA. Trace shows rapid transition from FRET $0.8(\mathrm{~A} / \mathrm{A}, \mathrm{A} / \mathrm{P})$ to FRET $0.4(\mathrm{CHI})^{20,37}$, followed by fluctuations between FRET 0.4 and 0.2 before adopting a long-lived FRET 0.2 state $(\mathrm{P} / \mathrm{P})$.

(f) Contour plot showing distribution of FRET values during translocation on slippery mRNA. The contour plot contains mixture of trajectories. $81 \%$ of traces show direct transitions from $A / A, A / P$ or $A / P^{*}$ to $P / P$. $19 \%$ of traces show transitions from $A / A, A / P$ or $A / P^{*}$ to $C H$ followed by fluctuations between $C H$ and $\mathrm{P} / \mathrm{P}$ states before transition to long-lived $\mathrm{P} / \mathrm{P}$ state. Traces are synchronized to the first transition below FRET 0.5. Histogram at the right shows distribution of FRET values after synchronization. Data are from 12 independent experiments $(\mathrm{N}=12)$. 

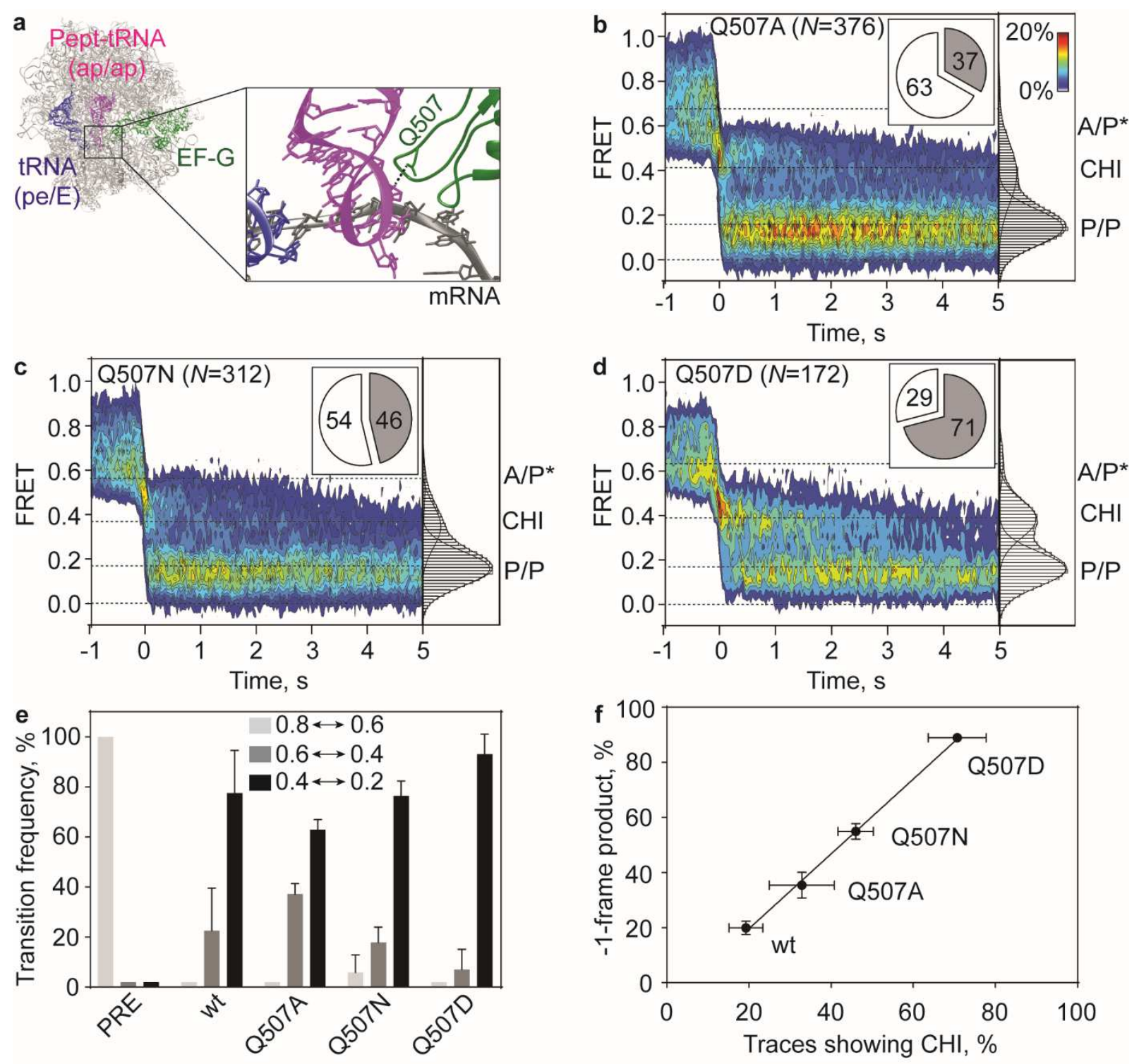

Figure 2. Frameshifting-prone translocation with EF-G(Q507) mutants.

(a) Schematic of an EF-G-ribosome complex in CHI state (adapted from PDB 4W2930). Pept-tRNA (magenta) and deacylated tRNA (blue) are in CHI states. The zoom-in shows residue Q507 at the tip of domain 4 of EF-G (green) in contact with the anticodon loop of pept-tRNA. The ribosome is shown in grey and the mRNA in black.

(b-d) Contour plots showing distribution of FRET values during translocation on slippery mRNA mediated by EF-G(Q507A) (b), EF-G(Q507N) (c), and EF-G(Q507D) (d). Histograms at the right show distribution of FRET values after synchronization to the first transition below FRET 0.5. Pie charts indicate percentage of smFRET traces showing prolonged fluctuations between $\mathrm{CHI}$ and $\mathrm{P} / \mathrm{P}$ states (dark grey) during translocation. Data are from at least 4 independent experiments ( $N=4$ for $Q 507 \mathrm{~A}, \mathrm{~N}=5$ for $\mathrm{Q} 507 \mathrm{~N}$, and $\mathrm{N}=9$ for Q507D). 
(e) Transition frequency between FRET states during translocation on slippery mRNA with Q507 mutants and EF-G(wt) (Supplementary Fig. 2 and Table 1). After addition of EF-G, transitions between FRET 0.4 $(\mathrm{CHI})$ and $0.2(\mathrm{P} / \mathrm{P})$ states are predominant. Shown are mean values with error bars representing the standard deviations.

(f) Correlation between frameshifting efficiency and the fraction of ribosomes sampling $\mathrm{CHI}$ states during translocation on slippery mRNA (Supplementary Fig. 3). Frameshifting efficiencies were measured at $22^{\circ} \mathrm{C}$ to match the conditions of the smFRET experiments. Shown are mean values with error bars representing the standard deviation. Black line indicates a linear fit with the slope of $1.3 \pm 0.1$, $\mathrm{R}^{2}=0.9982$. 
a Pept-tRNA ${ }^{\text {tys }}$-BHQ2
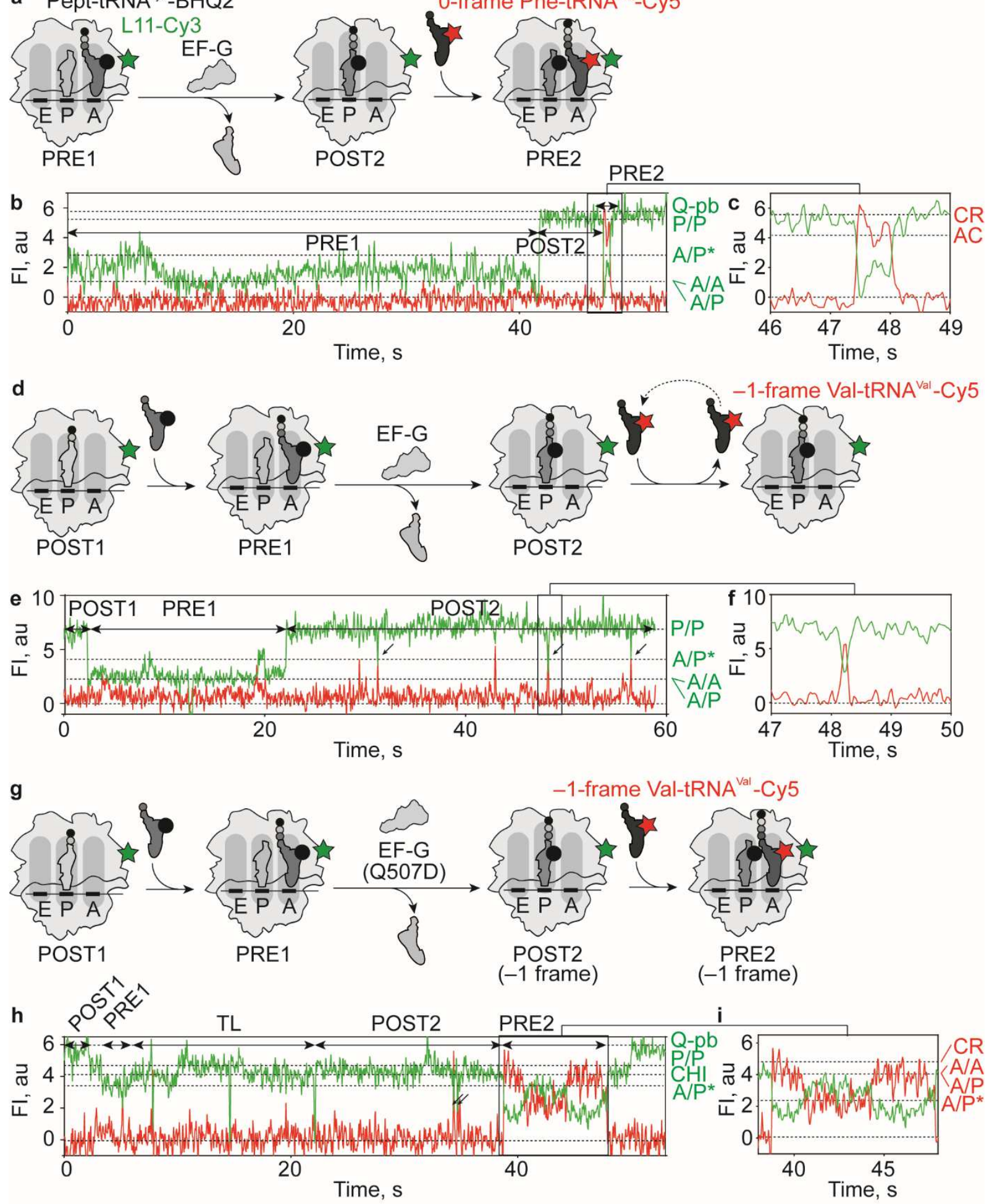

Figure 3. Translocation of pept-tRNA ${ }^{\text {Lys }}$ and incorporation of 0 - and-1-frame aa-tRNAs.

(a) Schematic of translocation of pept-tRNA ${ }^{\text {Lys }}$-BHQ2 (black circle) from the $A$ to the $P$ site on nonslippery mRNA by EF-G(wt) and subsequent incorporation of the cognate 0 -frame Phe-tRNA ${ }^{\text {Phe }}$-Cy5 (red star). 
(b) Representative time trace of pept-tRNA ${ }^{\text {Lys }}$-BHQ2 translocation and incorporation of Phe-tRNA ${ }^{\text {Phe }}$-Cy5 (box). Fl, fluorescence; $\mathrm{Q}-\mathrm{pb}$, photobleaching of BHQ2. Green labels at the right $\mathrm{Y}$-axis indicate the states monotored by Cy fluorescence.

(c) Zoom-in into Phe-tRNA ${ }^{\text {Phe }}$-Cy5 binding to POST2 forming PRE2 complexes showing FRET. The magnitude of the FRET change is consistent with previously characterized steps of codon recognition (CR) and accommodation (AC) ${ }^{38}$. Red labels indicate positions of Phe-tRNA states monitored by FRET to Cy5.

(d) Schematic of translocation of pept-tRNA ${ }^{\text {Lys }}$-BHQ2 from the A to the P site on non-slippery mRNA by

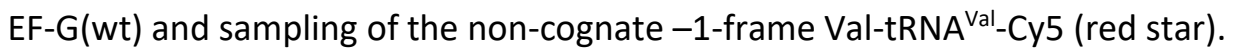

(e) Representative time trace of pept-tRNA ${ }^{\text {Lys }}$-BHQ2 translocation (one frame) and subsequent sampling of POST2 complexes by the near-cognate -1-frame tRNA ${ }^{\text {Val }}$-Cy5 (arrows).

(f) Zoom-in into transient binding of -1-frame Val-tRNA ${ }^{\text {Val }-C y 5}$ to POST2 complexes.

(g) Schematic of translocation of pept-tRNA ${ }^{\text {Lys }}$-BHQ2 from the A to the P site on slippery mRNA by EF$\mathrm{G}(\mathrm{Q} 507 \mathrm{D})$ and incorporation of the-1-frame Val-tRNA ${ }^{\mathrm{Val}}-\mathrm{Cy} 5$ (red star).

(h) Representative time trace of pept-tRNA ${ }^{\text {Lys }}$-BHQ2 translocation and subsequent incorporation of -1frame Val-tRNA ${ }^{\mathrm{Val}}$-Cy5 (box).

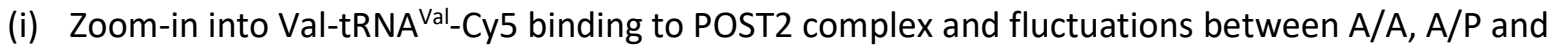
$\mathrm{A} / \mathrm{P}^{*}$ states. 
a

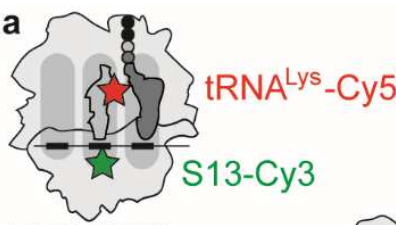

PRE (P/P)

FRET 0.9

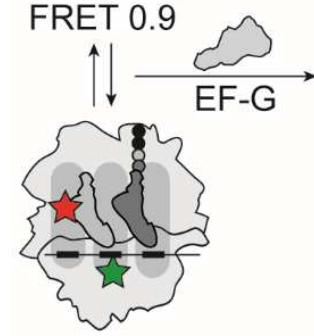

PRE (P/E)

FRET 0.6 b

Slippery mRNA

$\frac{\frac{\mathrm{fM}}{\mathrm{AUG}}}{\mathrm{fM}} \frac{\frac{A}{\mathrm{GCA}} \frac{K}{A A A} \frac{K}{\mathrm{~A}} \frac{K}{\mathrm{~K} A G} \frac{F}{\mathrm{UUC}}}{V} \quad \begin{array}{r}0 \text { frame } \\ -1 \text { frame }\end{array}$

Non-slippery mRNA

$\frac{f M}{A \cup G} \frac{A}{G C U} \frac{K}{A A G} \frac{K}{A A G} \frac{F}{U U C} \quad 0$ frame

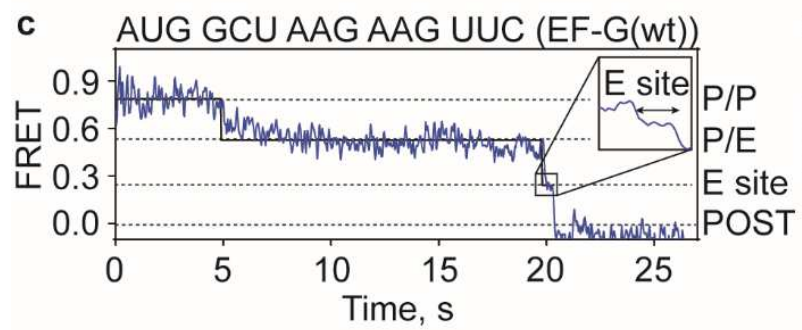

e AUG GCAAAAAAG UUC (Q507D)
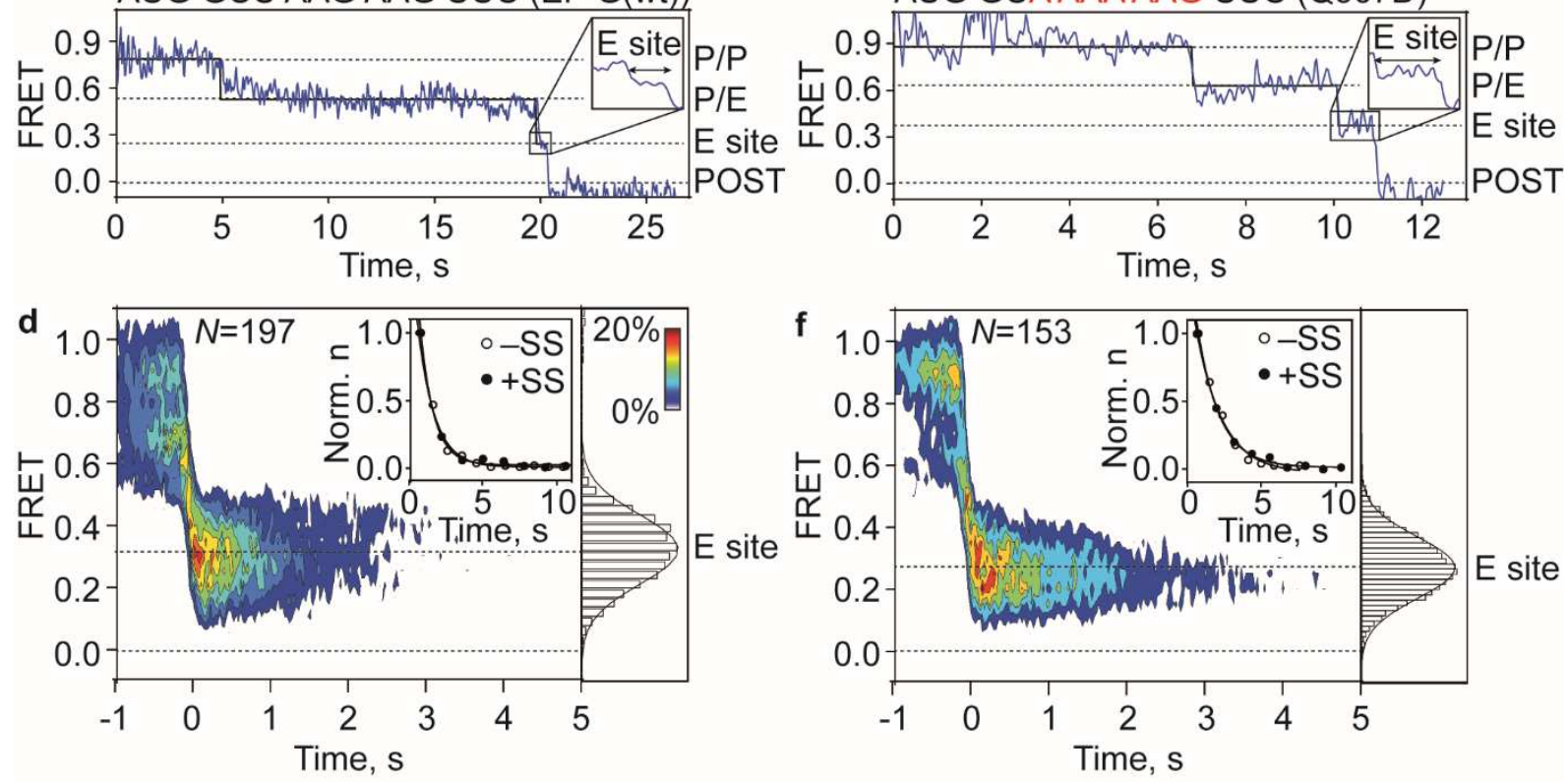

Figure 4. Translocation trajectory of deacylated tRNA.

(a) Schematic of smFRET experiment monitoring movement of tRNA ${ }^{\text {Lys }}$-Cy5 (Cy5; red star) relative to protein S13-Cy3 (green star). Translocation is induced by addition of EF-G. FRET values corresponding to $\mathrm{P}, \mathrm{P} / \mathrm{E}$ and $\mathrm{E}$ states were determined in independent experiments (Supplementary Fig. 5 and 6).

(b) Coding sequences of mRNA constructs. Slippery sequence encodes fMet-Ala-Lys-Lys-Phe in 0 frame and fMet-Ala-Lys-Lys-Val in -1 frame Non-slippery mRNA encodes only 0-frame fMet-Ala-Lys-Lys-Phe peptide because tRNA ${ }^{\text {Lys }}$ does not base pair with the -1-frame GAA.

(c) Representative smFRET time trace of tRNA translocation on non-slippery mRNA in the presence of $\mathrm{EF}-\mathrm{G}(\mathrm{wt})$ showing step-wise transition from FRET $0.9(\mathrm{P} / \mathrm{P})$ to $0.6(\mathrm{P} / \mathrm{E})$ to 0.3 (E site) to 0.0 (dissociation).

(d) Contour plot showing distribution of FRET efficiencies during translocation on non-slippery mRNA by EF-G(wt). Transitions occur either from FRET 0.9 (P site) or 0.6 (P/E ) to FRET 0.3 (E site). Traces are 
synchronized to the first transition below FRET 0.5. Histogram at the right shows distribution of FRET values after synchronization. Inset shows rates and curve fits of tRNA dissociation from E site on slippery (closed circles) and non-slippery (open circles) mRNA (Supplementary Fig. 6b and Table 2).

Normalization was performed by division by the number of transitions (n). Data are from 4 independent experiments $(\mathrm{N}=4)$.

(e) Representative smFRET time trace of tRNA translocation on slippery mRNA in the presence of EFG(Q507D) showing step-wise transition from FRET 0.9 (P site) to 0.6 (P/E ) to 0.3 (E site) to 0.0 (dissociation), similar to EF-G(wt) (c).

(f) Contour plot showing the distribution of FRET efficiencies during translocation on slippery mRNA by EF-G(Q507D). Transitions occur either from FRET 0.9 (P site) or 0.6 (P/E ) to FRET 0.3 (E site). Histogram at the right shows distribution of FRET values after synchronization to the first transition below FRET 0.5. Inset shows rates and curve fits of tRNA dissociation from E site on slippery (closed circles) and nonslippery (open circles) mRNA. Normalization was performed by division by the number of transitions ( $\mathrm{n}$ ) (Supplementary Fig. $6 \mathrm{c}$ and Table 2). Data are from 3 independent experiments $(\mathrm{N}=3)$. 

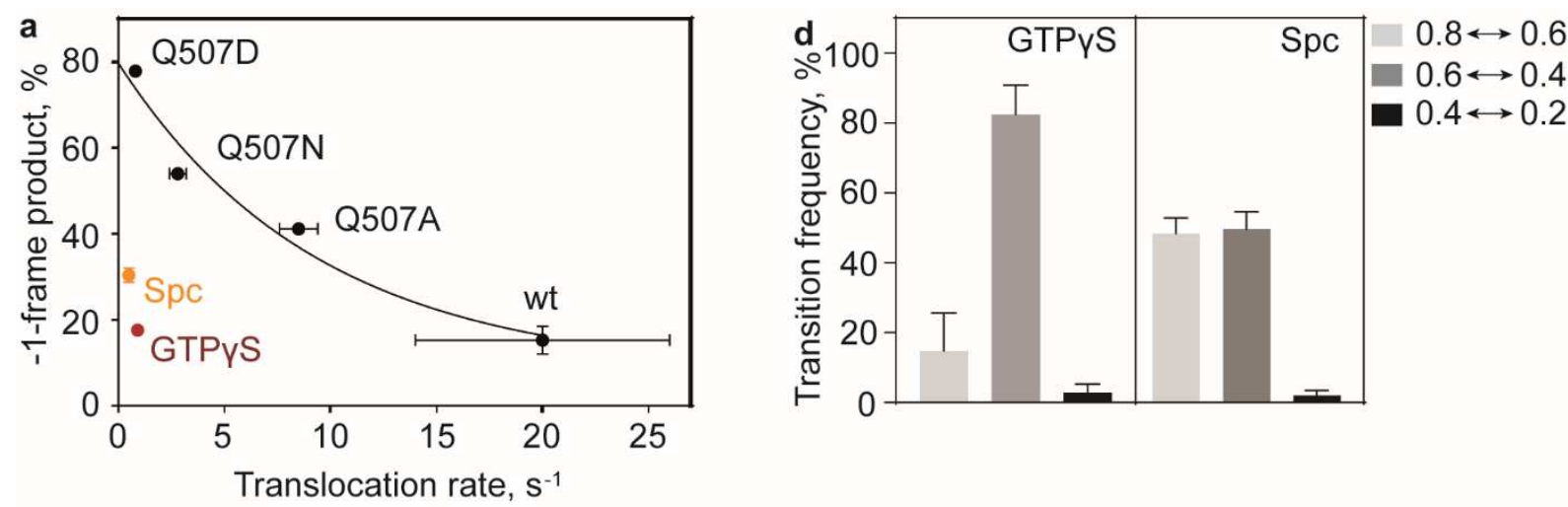

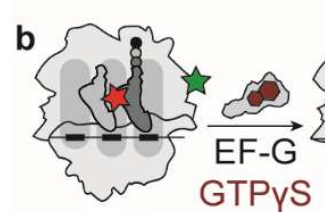

PRE

FRET 0.8

FRET 0.6
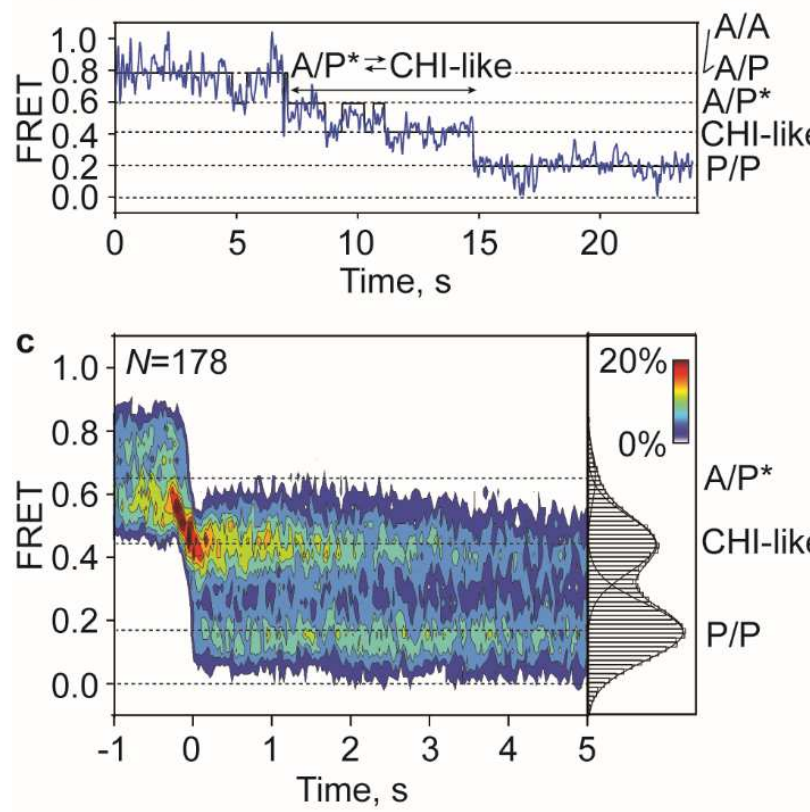

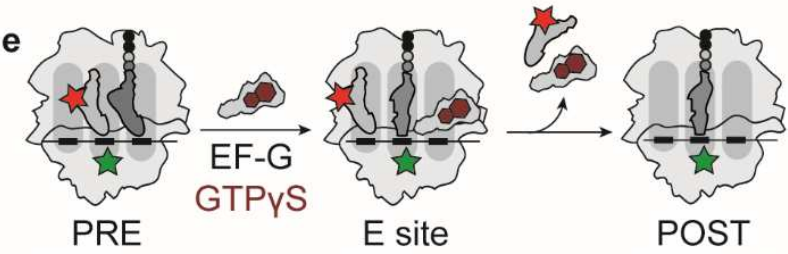

FRET 0.9 FRET 0.6

FRET 0.0
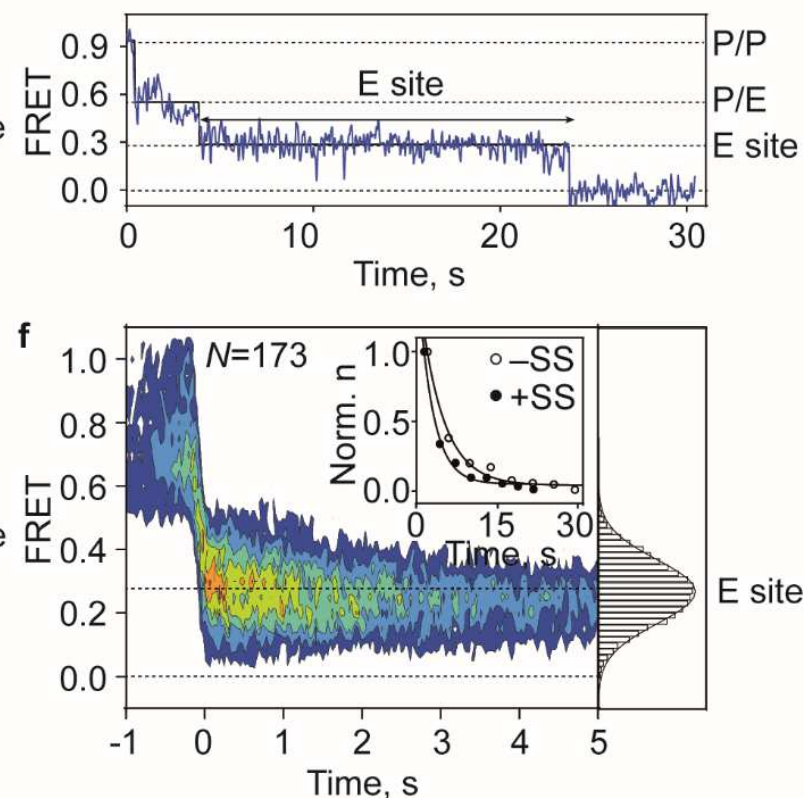

Figure 5. Translocation on slippery mRNA with EF-G(wt)-GTPYS.

(a) Correlation between frameshifting and ensemble translocation rate. Frameshifting efficiencies were measured at $37^{\circ} \mathrm{C}$. Translocation rates of EF-G(wt) and Q507 mutants are from ${ }^{16}$, of GTP $\mathrm{SS}$ (brown) from ${ }^{41}$ and of Spc (orange) from ${ }^{57}$.

(b) Above: schematic of smFRET experiment monitoring movement of pept-tRNA ${ }^{\text {Lys }}$-Cy5 (red stars) relative to L11-Cy3 (green star) byEF-G(wt)-GTPyS (brown hexagon). Below: representative smFRET trace of pept-tRNA translocation by EF-G(wt)-GTP $\mathrm{S}$ with fluctuations between FRET $0.8(\mathrm{~A} / \mathrm{A}, \mathrm{A} / \mathrm{P})$ and $0.6\left(\mathrm{~A} / \mathrm{P}^{*}\right)$ followed by fluctuations between FRET $0.4(\mathrm{CHI})$ and 0.6 . 
(c) Contour plot showing distribution of FRET values during translocation of pept-tRNA on slippery mRNA by EF-G(wt)-GTP $\mathrm{S}$. The contour plot contains mixture of trajectories with either direct transitions from $A / A, A / P$ or $A / P^{*}$ to $P / P(28 \%)$ or fluctuations between $A / P^{*}$ and $C H I$-like states before transition to $\mathrm{P} / \mathrm{P}$ (72\%). Traces are synchronized to the first transition below FRET 0.5. Histogram at the right shows distribution of FRET values after synchronization. Data are from 6 independent experiments $(\mathrm{N}=6)$.

(d) Transition frequencies between FRET states during pept-tRNA translocation on slippery mRNA by EFG(wt) - GTPyS (Supplementary Fig. 7b and Table 1) and in the presence of Spc (Table 1).

(e) Above: schematic of smFRET experiment with tRNA ${ }^{\text {Lys }}$-Cy5 (red star) moving relative to protein S13Cy3 (green star) during translocation by EF-G(wt)-GTPyS. Below: representative smFRET trace of translocation by EF-G(wt)-GTPyS with stepwise transition from FRET $0.9(P / P)$ to $0.6(P / E)$ to $0.3(E)$ to 0.0 (dissociation).

(f) Contour plot showing distribution of FRET values during translocation of deacylated tRNA on slippery mRNA by EF-G(wt) - GTPYS. Transitions occur either from FRET 0.9 (P/P) or 0.6 (P/E) to FRET $0.3(\mathrm{E})$. Traces were synchronized to the first transition below FRET 0.5. Histogram at the right shows distribution of FRET values after synchronization. Inset shows rates and curve fit of tRNA dissociation from E site on slippery (closed circles) and non-slippery (open circles) mRNA (Supplementary Fig. 7c and Table 2). Normalization was performed by division by the number of transitions ( $n$ ). Data are from 3 independent experiments $(\mathrm{N}=3)$. 

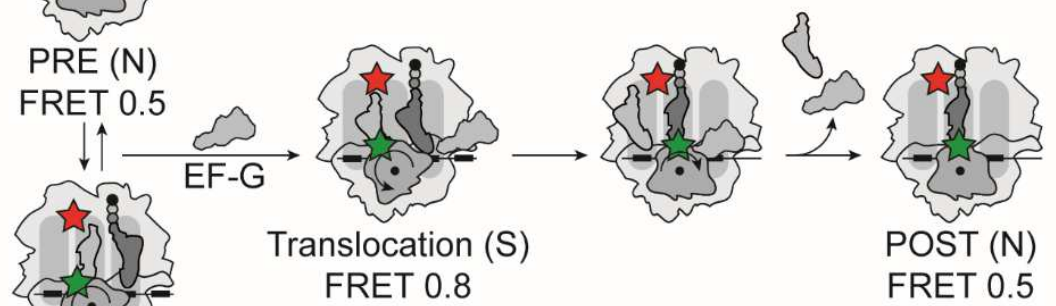

PRE (S)

FRET 0.8
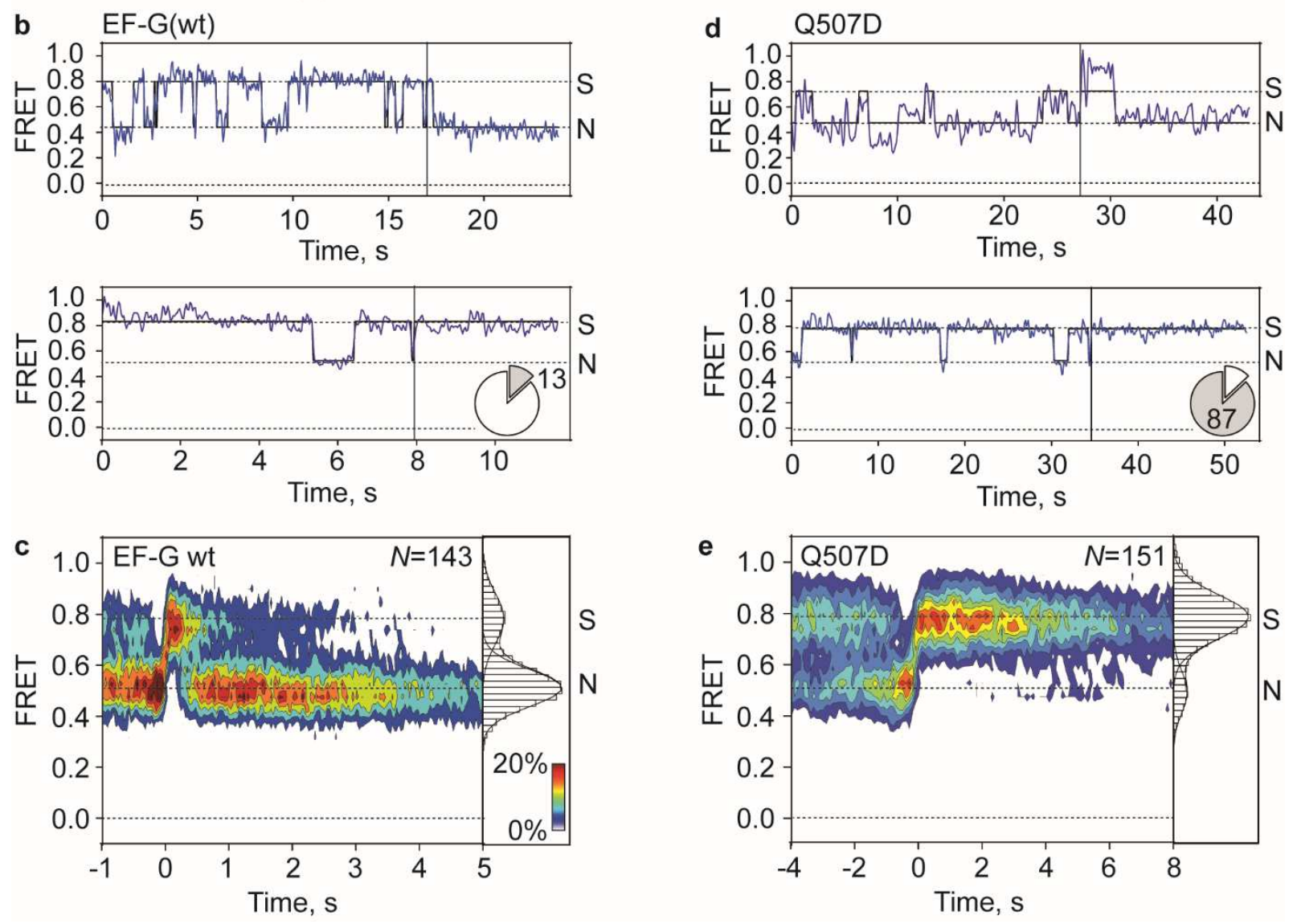

Figure 6. SSU head domain swiveling during translocation on slippery mRNA.

(a) Schematic of smFRET experiment. Movement of SSU head domain during EF-G-induced translocation is monitored with FRET labels on ribosomal proteins S13 (S13-Cy3, green star) and L33 (L33-Cy5, red star). FRET values representing the non-swiveled $(\mathrm{N})$ and swiveled $(\mathrm{S})$ states are determined in independent experiments (Supplementary Fig. 9 and Table 3).

(b) Representative smFRET time traces for SSU head movements during EF-G(wt)-induced translocation. The majority of traces (upper panel) show fluctuations between FRET 0.8 (S) and 0.5 (N) followed by a stable FRET $0.5(\mathrm{~N})$ state after translocation. 13\% of traces (lower panel) show no transition to the $\mathrm{N}$ 
state in the time course of the experiment. Pie charts indicate the percentage of traces ending in $\mathrm{N}$ (white) or S (grey) state.

(c) Contour plot showing distribution of FRET values representing SSU head movement during translocation on slippery mRNA by EF-G(wt). Traces were synchronized to the last transition to FRET 0.8 (S). The duration of the last FRET 0.8 state is an estimate for the duration of translocation, because back swiveling occurs simultaneously with the dissociation of EF-G from the ribosome after translocation ${ }^{23}$. Histogram at the right shows distribution of FRET values after synchronization. Data are from 4 independent experiments ( $\mathrm{N}=4)$.

(d) Representative smFRET time traces for SSU head domain movement during translocation on slippery mRNA with EF-G(Q507D). A small fraction of traces (upper panel) show fluctuations between FRET 0.8 $(\mathrm{S})$ and $0.5(\mathrm{~N})$ and end in a stable FRET $0.5(\mathrm{~N})$ state after translocation. $87 \%$ of traces (lower panel) show no transition to the $\mathrm{N}$ state in the time course of the experiment.

(e) Contour plot showing distribution of FRET values representing SSU head domain movement during translocation on slippery mRNA by EF-G(Q507D). In most traces, back swiveling to the $\mathrm{N}$ state is not observed in the time course of the experiment. Traces were synchronized to the last transition to FRET 0.8 (S). Histogram at the right shows distribution of FRET values after synchronization. Data are from 3 independent experiments $(\mathrm{N}=3)$. 

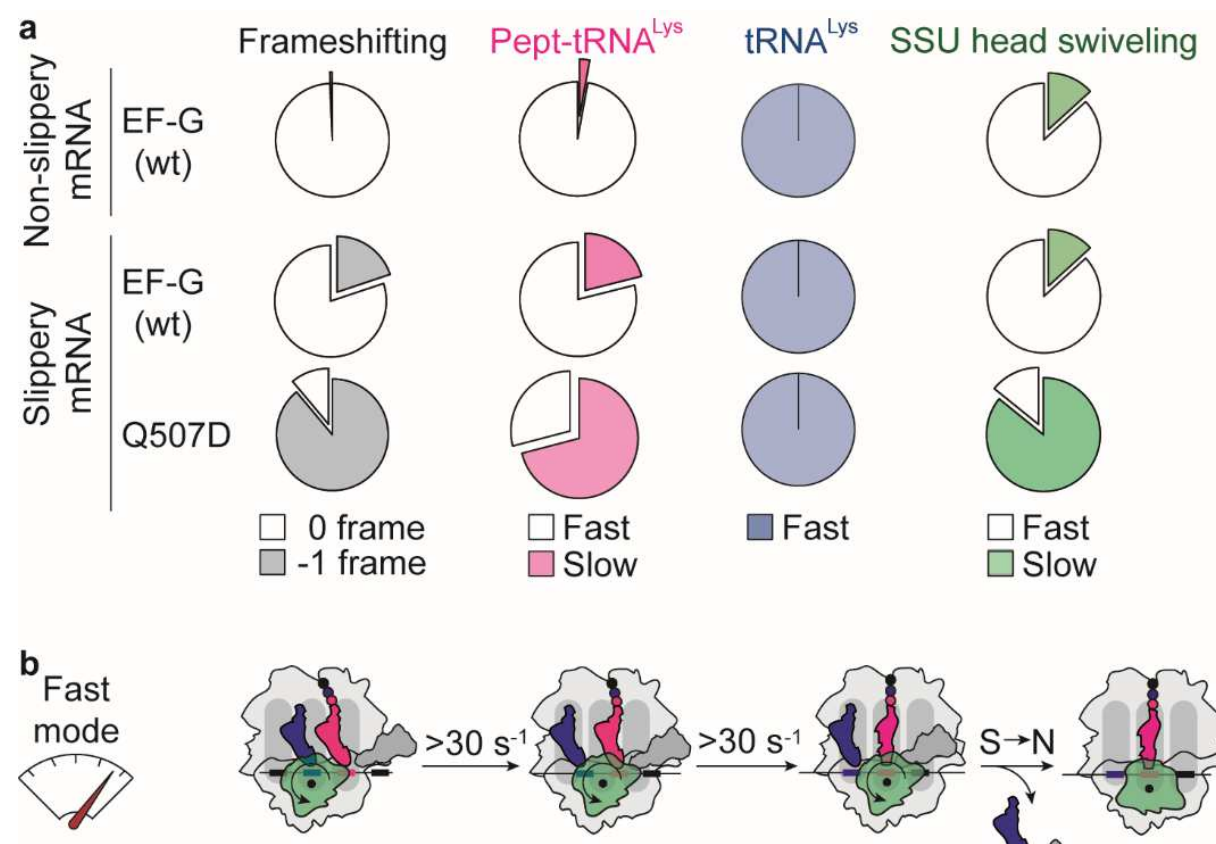

$\mathrm{P} / \mathrm{E}$ A/P

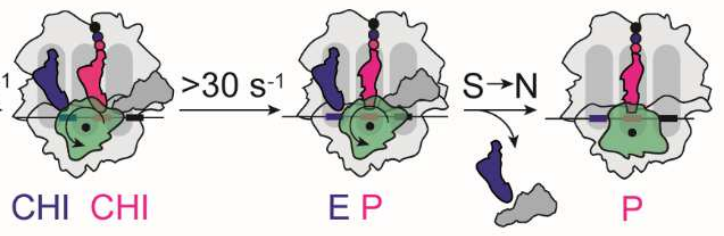

.

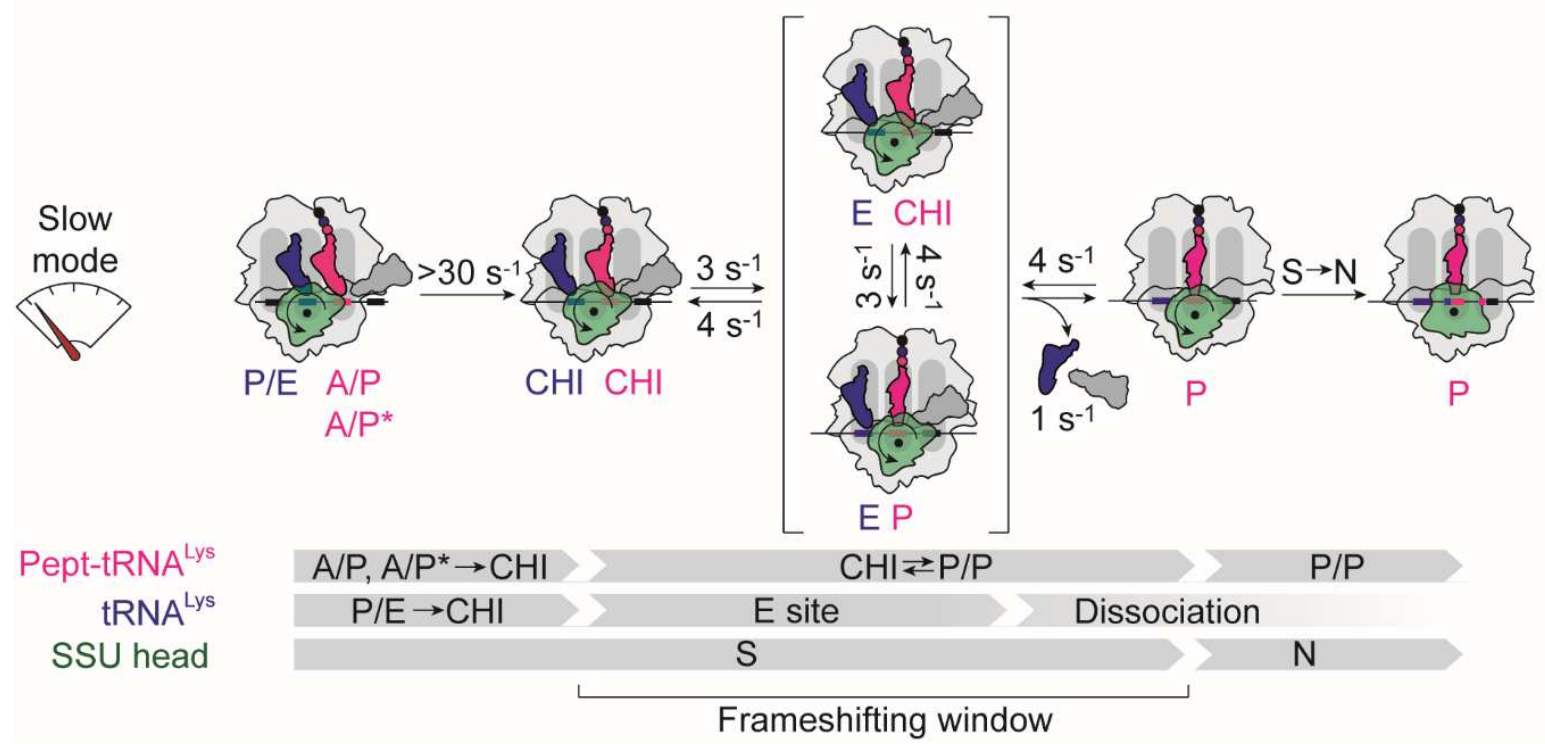

Figure 7. Translocation trajectories correlating with frameshifting.

(a) Pie charts comparing the frameshifting efficiency (grey) with the distribution of translocation rates for pept-tRNA (magenta) and deacylated tRNA (blue) and SSU head domain back rotation (green) on non-slippery and slippery mRNA with EF-G(wt) and EF-G(Q507D).

(b) Kinetic model of translocation on slippery mRNA. Majority of ribosomes translocate in fast mode with tRNAs moving synchronously to the POST state; back swiveling of the SSU head domain completes translocation. A fraction of ribosomes translocates in slow mode where pept-tRNA is trapped fluctuating between $\mathrm{CHI}$ and $\mathrm{P} / \mathrm{P}$ instead of moving to the POST state. Deacylated tRNA translocates rapidly and dissociates from the E site allowing pept-tRNA to sample 0- and-1-frame codons. SSU head closure is 
delayed due to prolonged fluctuations of pept-tRNA. Rates of the elemental reactions for pept-tRNA are indicated. 


\section{Tables}

Table 1. Kinetics of pept-tRNA ${ }^{\text {Lys }}$ fluctuations during translocation on slippery mRNA.

\begin{tabular}{|c|c|c|c|c|}
\hline \multirow[b]{2}{*}{ EF-G } & \multirow[b]{2}{*}{$k_{T L}, \mathrm{~s}^{-1}(N)$} & \multirow[b]{2}{*}{ FRET, $\mu \pm s . d$. } & \multicolumn{2}{|c|}{ Transition rates during translocation $k, \mathrm{~s}^{-1}(\mathrm{n})$} \\
\hline & & & $\begin{array}{l}0.6 \rightarrow 0.4 \\
0.4 \rightarrow 0.6\end{array}$ & $\begin{array}{l}0.4 \rightarrow 0.2 \\
0.2 \rightarrow 0.4\end{array}$ \\
\hline wt & $0.2 \pm 0.1(102)$ & $\begin{array}{l}0.6 \pm 0.1 \\
0.4 \pm 0.1 \\
0.2 \pm 0.1\end{array}$ & $\begin{array}{c}\text { n.d. }{ }^{a}(64) \\
\text { n.d (61) }\end{array}$ & $\begin{array}{l}2.6 \pm 0.6(186) \\
2.7 \pm 1.4(148)\end{array}$ \\
\hline Q507A & $0.1 \pm 0.1(110)$ & $\begin{array}{l}0.6 \pm 0.1 \\
0.4 \pm 0.1 \\
0.2 \pm 0.1\end{array}$ & $\begin{array}{l}3.9 \pm 0.7(79) \\
5.9 \pm 1.9(83)\end{array}$ & $\begin{array}{l}3.0 \pm 1.2(152) \\
2.8 \pm 0.6(138)\end{array}$ \\
\hline Q507N & $0.2 \pm 0.1(106)$ & $\begin{array}{l}0.6 \pm 0.1 \\
0.4 \pm 0.1 \\
0.2 \pm 0.1\end{array}$ & $\begin{array}{l}\text { n.d. (61) } \\
\text { n.d. (64) }\end{array}$ & $\begin{array}{l}3.7 \pm 0.6(261) \\
3.8 \pm 1.1(228)\end{array}$ \\
\hline Q507D & $0.3 \pm 0.1(90)$ & $\begin{array}{l}0.6 \pm 0.1 \\
0.4 \pm 0.1 \\
0.2 \pm 0.1\end{array}$ & $\begin{array}{l}\text { n.d. (22) } \\
\text { n.d. (21) }\end{array}$ & $\begin{array}{l}2.8 \pm 0.2(324) \\
3.7 \pm 0.2(315)\end{array}$ \\
\hline wt-GTPyS & $0.2 \pm 0.1(128)$ & $\begin{array}{l}0.6 \pm 0.1 \\
0.4 \pm 0.1 \\
0.2 \pm 0.1\end{array}$ & $\begin{array}{l}7.1 \pm 0.9(292) \\
6.3 \pm 0.9(266)\end{array}$ & $\begin{array}{l}\text { n.d. (9) } \\
\text { n.d. (9) }\end{array}$ \\
\hline$w t+S p c$ & n.a. ${ }^{b}$ & $\begin{array}{l}0.8 \pm 0.1 \\
0.6 \pm 0.1 \\
0.4 \pm 0.1 \\
0.2 \pm 0.1\end{array}$ & $\begin{array}{c}3.5 \pm 0.4 \mathrm{~s}^{-1}(809)^{\mathrm{c}} \\
6.1 \pm 1.2 \mathrm{~s}^{-1}(939)^{\mathrm{d}} \\
5.2 \pm 1.2(937) \\
2.4 \pm 0.2(870)\end{array}$ & $\begin{array}{l}\text { n.d. (39) } \\
\text { n.d. (29) }\end{array}$ \\
\hline
\end{tabular}

$N$, number of traces

$\mu$, mean of the Gaussian distribution

$n$, number of transitions

All rates were corrected for photobleaching of the FRET dyes (Methods) and are shown as mean $\pm s$.d. with $R^{2} \geq 0.96$ in all cases.

${ }^{a}$ number of fluctuations was too small to calculate transition rates

${ }^{b}$ The majority of traces did not reach the POST state and the $k T L$ rate was limited by the photobleaching of the FRET dyes.

c Transitions from FRET 0.8 to 0.6 .

${ }^{\mathrm{d}}$ Transitions from FRET 0.6 to 0.8 . 
Table 2. Kinetics of deacylated tRNA ${ }^{\text {Lys }}$ dissociation from the $E$ site.

\begin{tabular}{|c|c|c|}
\hline \multirow{2}{*}{ EF-G } & \multicolumn{2}{|c|}{ Dissociation rate from $E$ site, $\mathrm{s}^{-1}(N)^{\mathrm{a}, \mathrm{b}}$} \\
\cline { 2 - 3 } & U AAG AAG (non-slippery) & A AAA AAG (slippery) \\
\hline wt & $0.9 \pm 0.1(196)$ & $1.0 \pm 0.1(169)$ \\
\hline Q507D & $0.6 \pm 0.1(175)$ & $0.5 \pm 0.1(152)$ \\
\hline wt-GTPYS & $0.2 \pm 0.1(205)$ & $0.3 \pm 0.1(173)$ \\
\hline wt-SPC & n.d. & $0.3 \pm 0.1(157)$ \\
\hline wt-FA & $<0.1 \pm 0.1^{\mathrm{c}}(169)$ & n.d. \\
\hline
\end{tabular}

${ }^{a} N$, number of traces

${ }^{b}$ All rates were corrected for photobleaching of the FRET dyes (Methods) and are shown as mean \pm s.d. from at least 3 independent experiments. $R^{2} \geq 0.96$ in all cases.

${ }^{\mathrm{C}}$ Rate was limited by the photobleaching of the FRET dyes.

Table 3. Kinetics of SSU head swiveling.

\begin{tabular}{|c|c|c|}
\hline \multirow{2}{*}{ EF-G } & \multicolumn{2}{|c|}{$k_{s \rightarrow N}, s^{-1}(n)^{a, b}$} \\
\cline { 2 - 3 } & G UUU AAG (non-slippery) & G GGA AAG (slippery) \\
\hline no EF-G & n.d. & $2.5 \pm 0.2(1975)$ \\
\hline wt & $2.2 \pm 0.3(149)$ & $1.9 \pm 0.1(124)$ \\
\hline Q507D & n.d. & $<0.1 \pm 0.1^{\mathrm{c}}(151)$ \\
\hline
\end{tabular}

${ }^{a} \mathrm{n}$, number of transitions

${ }^{b}$ Rates are shown as mean \pm s.d. from at least 3 independent experiments. $R^{2} \geq 0.99$ in all cases.

${ }^{\mathrm{C}}$ Rate was limited by the photobleaching of the FRET dyes. 


\section{References}

1. Kelly JA, et al. Structural and functional conservation of the programmed -1 ribosomal frameshift signal of SARS coronavirus 2 (SARS-CoV-2). J Biol Chem 295, 10741-10748 (2020).

2. Kendra JA, et al. Functional and structural characterization of the chikungunya virus translational recoding signals. J Biol Chem 293, 17536-17545 (2018).

3. Kendra JA, et al. Ablation of Programmed -1 Ribosomal Frameshifting in Venezuelan Equine Encephalitis Virus Results in Attenuated Neuropathogenicity. J Virol 91, (2017).

4. Moomau C, Musalgaonkar S, Khan YA, Jones JE, Dinman JD. Structural and Functional Characterization of Programmed Ribosomal Frameshift Signals in West Nile Virus Strains Reveals High Structural Plasticity Among cis-Acting RNA Elements. J Biol Chem 291, 15788-15795 (2016).

5. Atkins JF, O'Connor KM, Bhatt PR, Loughran G. From Recoding to Peptides for MHC Class I Immune Display: Enriching Viral Expression, Virus Vulnerability and Virus Evasion. Viruses 13, (2021).

6. Napthine $\mathrm{S}$, Hill $\mathrm{CH}$, Nugent HCM, Brierley I. Modulation of Viral Programmed Ribosomal Frameshifting and Stop Codon Readthrough by the Host Restriction Factor Shiftless. Viruses 13, (2021).

7. Napthine S, Bell S, Hill CH, Brierley I, Firth AE. Characterization of the stimulators of proteindirected ribosomal frameshifting in Theiler's murine encephalomyelitis virus. Nucleic Acids Res 47, 8207-8223 (2019).

8. Drummond DA, Wilke CO. The evolutionary consequences of erroneous protein synthesis. Nat Rev Genet 10, 715-724 (2009).

9. Fu C, Parker J. A ribosomal frameshifting error during translation of the argI mRNA of Escherichia coli. Mol Gen Genet 243, 434-441 (1994).

10. Belew AT, Dinman JD. Cell cycle control (and more) by programmed -1 ribosomal frameshifting: implications for disease and therapeutics. Cell Cycle 14, 172-178 (2015).

11. Gurvich OL, Baranov PV, Zhou J, Hammer AW, Gesteland RF, Atkins JF. Sequences that direct significant levels of frameshifting are frequent in coding regions of Escherichia coli. EMBO J 22, 5941-5950 (2003).

12. Belew AT, Hepler NL, Jacobs JL, Dinman JD. PRFdb: a database of computationally predicted eukaryotic programmed -1 ribosomal frameshift signals. BMC Genomics 9, 339 (2008). 
13. Devaraj A, Shoji S, Holbrook ED, Fredrick K. A role for the $30 \mathrm{~S}$ subunit $E$ site in maintenance of the translational reading frame. RNA 15, 255-265 (2009).

14. Kurland CG. Translational accuracy and the fitness of bacteria. Annu Rev Genet 26, 29-50 (1992).

15. Bock LV, Caliskan N, Korniy N, Peske F, Rodnina MV, Grubmuller H. Thermodynamic control of -1 programmed ribosomal frameshifting. Nat Commun 10, 4598 (2019).

16. Peng BZ, Bock LV, Belardinelli R, Peske F, Grubmuller H, Rodnina MV. Active role of elongation factor $\mathrm{G}$ in maintaining the mRNA reading frame during translation. Sci Adv 5, eaax8030 (2019).

17. Niblett D, et al. Mutations in domain IV of elongation factor EF-G confer -1 frameshifting. RNA 27, 40-53 (2021).

18. Zhou J, Lancaster L, Donohue JP, Noller HF. Spontaneous ribosomal translocation of mRNA and tRNAs into a chimeric hybrid state. Proc Natl Acad Sci U S A 116, 7813-7818 (2019).

19. Petrychenko V, Peng BZ, de APSAC, Peske F, Rodnina MV, Fischer N. Structural mechanism of GTPase-powered ribosome-tRNA movement. Nat Commun 12, 5933 (2021).

20. Adio S, Senyushkina T, Peske F, Fischer N, Wintermeyer W, Rodnina MV. Fluctuations between multiple EF-G-induced chimeric tRNA states during translocation on the ribosome. Nat Commun 6, 7442 (2015).

21. Frank J, Agrawal RK. A ratchet-like inter-subunit reorganization of the ribosome during translocation. Nature 406, 318-322 (2000).

22. Sharma H, Adio S, Senyushkina T, Belardinelli R, Peske F, Rodnina MV. Kinetics of Spontaneous and EF-G-Accelerated Rotation of Ribosomal Subunits. Cell Rep 16, 2187-2196 (2016).

23. Belardinelli $\mathrm{R}$, et al. Choreography of molecular movements during ribosome progression along mRNA. Nat Struct Mol Biol 23, 342-348 (2016).

24. Pulk A, Cate JH. Control of ribosomal subunit rotation by elongation factor G. Science 340, 1235970 (2013).

25. Munro JB, Wasserman MR, Altman RB, Wang L, Blanchard SC. Correlated conformational events in EF-G and the ribosome regulate translocation. Nat Struct Mol Biol 17, 1470-1477 (2010). 
26. Wasserman MR, Alejo JL, Altman RB, Blanchard SC. Multiperspective smFRET reveals ratedetermining late intermediates of ribosomal translocation. Nat Struct Mol Biol 23, 333-341 (2016).

27. Fei J, Bronson JE, Hofman JM, Srinivas RL, Wiggins CH, Gonzalez RL, Jr. Allosteric collaboration between elongation factor $G$ and the ribosomal $L 1$ stalk directs tRNA movements during translation. Proc Natl Acad Sci U S A 106, 15702-15707 (2009).

28. Guo Z, Noller HF. Rotation of the head of the 30 S ribosomal subunit during mRNA translocation. Proc Natl Acad Sci U S A 109, 20391-20394 (2012).

29. Ramrath DJ, et al. Visualization of two transfer RNAs trapped in transit during elongation factor G-mediated translocation. Proc Natl Acad Sci U S A 110, 20964-20969 (2013).

30. Zhou J, Lancaster L, Donohue JP, Noller HF. How the ribosome hands the A-site tRNA to the P site during EF-G-catalyzed translocation. Science 345, 1188-1191 (2014).

31. Carbone CE, Loveland AB, Gamper HB, Jr., Hou YM, Demo G, Korostelev AA. Time-resolved cryoEM visualizes ribosomal translocation with EF-G and GTP. Nat Commun 12, 7236 (2021).

32. Rundlet EJ, et al. Structural basis of early translocation events on the ribosome. Nature 595, 741745 (2021).

33. Savelsbergh A, Matassova NB, Rodnina MV, Wintermeyer W. Role of domains 4 and 5 in elongation factor $\mathrm{G}$ functions on the ribosome. J Mol Biol 300, 951-961 (2000).

34. Cunha CE, Belardinelli R, Peske F, Holtkamp W, Wintermeyer W, Rodnina MV. Dual use of GTP hydrolysis by elongation factor $\mathrm{G}$ on the ribosome. Translation (Austin) 1, e24315 (2013).

35. Pan D, Kirillov SV, Cooperman BS. Kinetically competent intermediates in the translocation step of protein synthesis. Mol Cell 25, 519-529 (2007).

36. Holtkamp W, Cunha CE, Peske F, Konevega AL, Wintermeyer W, Rodnina MV. GTP hydrolysis by EF-G synchronizes tRNA movement on small and large ribosomal subunits. EMBO J 33, 1073-1085 (2014).

37. Chen $C$, et al. Single-molecule fluorescence measurements of ribosomal translocation dynamics. Mol Cell 42, 367-377 (2011).

38. Geggier $\mathrm{P}$, et al. Conformational sampling of aminoacyl-tRNA during selection on the bacterial ribosome. J Mol Biol 399, 576-595 (2010). 
39. Kuhle B, Ficner R. A monovalent cation acts as structural and catalytic cofactor in translational GTPases. EMBO J 33, 2547-2563 (2014).

40. Rodnina MV, Savelsbergh A, Katunin VI, Wintermeyer W. Hydrolysis of GTP by elongation factor $\mathrm{G}$ drives tRNA movement on the ribosome. Nature 385, 37-41 (1997).

41. Katunin VI, Savelsbergh A, Rodnina MV, Wintermeyer W. Coupling of GTP hydrolysis by elongation factor $\mathrm{G}$ to translocation and factor recycling on the ribosome. Biochemistry 41, 12806-12812 (2002).

42. Borovinskaya MA, Shoji S, Holton JM, Fredrick K, Cate JHD. A steric block in translation caused by the antibiotic spectinomycin. ACS Chem Biol 2, 545-552 (2007).

43. Savelsbergh A, Katunin VI, Mohr D, Peske F, Rodnina MV, Wintermeyer W. An elongation factor G-induced ribosome rearrangement precedes tRNA-mRNA translocation. Mol Cell 11, 1517-1523 (2003).

44. Caliskan N, Peske F, Rodnina MV. Changed in translation: mRNA recoding by -1 programmed ribosomal frameshifting. Trends Biochem Sci 40, 265-274 (2015).

45. Caliskan N, Katunin VI, Belardinelli R, Peske F, Rodnina MV. Programmed -1 frameshifting by kinetic partitioning during impeded translocation. Cell 157, 1619-1631 (2014).

46. Chen J, Petrov A, Johansson M, Tsai A, O'Leary SE, Puglisi JD. Dynamic pathways of -1 translational frameshifting. Nature 512, 328-332 (2014).

47. Kim HK, Liu F, Fei J, Bustamante C, Gonzalez RL, Jr., Tinoco I, Jr. A frameshifting stimulatory stem loop destabilizes the hybrid state and impedes ribosomal translocation. Proc Natl Acad Sci U S A 111, 5538-5543 (2014).

48. Yan S, Wen JD, Bustamante C, Tinoco I, Jr. Ribosome excursions during mRNA translocation mediate broad branching of frameshift pathways. Cell 160, 870-881 (2015).

49. Chen C, et al. Dynamics of translation by single ribosomes through mRNA secondary structures. Nat Struct Mol Biol 20, 582-588 (2013).

50. Caliskan N, Wohlgemuth I, Korniy N, Pearson M, Peske F, Rodnina MV. Conditional Switch between Frameshifting Regimes upon Translation of dnaX mRNA. Mol Cell 66, 558-567 e554 (2017). 
51. Desai VP, et al. Co-temporal Force and Fluorescence Measurements Reveal a Ribosomal Gear Shift Mechanism of Translation Regulation by Structured mRNAs. Mol Cell 75, 1007-1019 e1005 (2019).

52. Bock LV, et al. Energy barriers and driving forces in tRNA translocation through the ribosome. Nat Struct Mol Biol 20, 1390-1396 (2013).

53. Rodnina MV, Wintermeyer W. GTP consumption of elongation factor Tu during translation of heteropolymeric mRNAs. Proc Natl Acad Sci U S A 92, 1945-1949 (1995).

54. Milon P, Konevega AL, Peske F, Fabbretti A, Gualerzi CO, Rodnina MV. Transient kinetics, fluorescence, and FRET in studies of initiation of translation in bacteria. Methods Enzymol 430, 130 (2007).

55. Korniy N, et al. Modulation of HIV-1 Gag/Gag-Pol frameshifting by tRNA abundance. Nucleic Acids Res 47, 5210-5222 (2019).

56. Bronson JE, Fei J, Hofman JM, Gonzalez RL, Jr., Wiggins $\mathrm{CH}$. Learning rates and states from biophysical time series: a Bayesian approach to model selection and single-molecule FRET data. Biophys J 97, 3196-3205 (2009).

57. Peske F, Savelsbergh A, Katunin VI, Rodnina MV, Wintermeyer W. Conformational changes of the small ribosomal subunit during elongation factor G-dependent tRNA-mRNA translocation. $J \mathrm{Mol}$ Biol 343, 1183-1194 (2004). 


\section{Supplementary Files}

This is a list of supplementary files associated with this preprint. Click to download.

- SupplementaryFigures.pdf

- nrreportingsummaryflatten.pdf 